Working Paper/Document de travail 2011-21

\title{
Fixed-Term and Permanent Employment Contracts: Theory and Evidence
}

by Shutao Cao, Enchuan Shao and Pedro Silos 
Bank of Canada Working Paper 2011-21

October 2011

\title{
Fixed-Term and Permanent Employment Contracts: Theory and Evidence
}

by

\author{
Shutao Cao, ${ }^{1}$ Enchuan Shao ${ }^{2}$ and Pedro Silos ${ }^{3}$ \\ ${ }^{1}$ Canadian Economic Analysis Department \\ Bank of Canada \\ Ottawa, Ontario, Canada K1A OG9 \\ shutacao@bankofcanada.ca \\ ${ }^{2}$ Currency Department \\ Bank of Canada \\ Ottawa, Ontario Canada K1A OG9 \\ eshao@bankofcanada.ca \\ ${ }^{3}$ Federal Reserve Bank of Atlanta \\ Atlanta, Georgia 30309 \\ pedro.silos@atl.frb.org
}

Bank of Canada working papers are theoretical or empirical works-in-progress on subjects in economics and finance. The views expressed in this paper are those of the authors.

No responsibility for them should be attributed to the Bank of Canada, the Federal Reserve Bank of Atlanta or the Federal Reserve System. 


\section{Acknowledgements}

We appreciate comments and suggestions from participants at the University of Iowa, the Bank of Canada, the Search and Matching Workshop in Konstanz (2010) (especially our discussant Georg Duernecker), Midwest Macroeconomics Meetings, Computing in Economics and Finance Meetings, the Canadian Economics Association Meetings, the Matched Employer-Employee Conference in Aarhus, and especially Shouyong Shi and David Andolfatto. Finally, we would like to thank Yves Decady at Statistics Canada for his assistance with the WES data. 


\begin{abstract}
This paper constructs a theory of the coexistence of fixed-term and permanent employment contracts in an environment with ex-ante identical workers and employers. Workers under fixed-term contracts can be dismissed at no cost while permanent employees enjoy labor protection. In a labor market characterized by search and matching frictions, firms find it optimal to discriminate by offering some workers a fixedterm contract while offering other workers a permanent contract. Match-specific quality between a worker and a firm determines the type of contract offered. We analytically characterize the firm's hiring and firing rules. Using matched employer-employee data from Canada, we estimate the model's parameters. Increasing the level of firing costs increases wage inequality and decreases the unemployment rate. The increase in inequality results from a larger fraction of temporary workers and not from an increase in the wage premium earned by permanent workers.
\end{abstract}

JEL classification: H29, J23, J38

Bank classification: Labour markets; Potential output; Productivity

\title{
Résumé
}

Les auteurs élaborent un cadre théorique pour expliquer la coexistence de contrats à durée déterminée et de contrats de travail permanents dans un milieu où travailleurs et employeurs sont a priori identiques. Les travailleurs temporaires sont licenciables sans frais, alors que les employés permanents jouissent d'une protection d'emploi. Sur un marché du travail caractérisé par des frictions dans la prospection et l'appariement, les entreprises jugent optimal d'opérer des distinctions en proposant à certains travailleurs un contrat à durée déterminée et à d'autres un contrat permanent. La qualité intrinsèque de l'appariement entre le travailleur et l'entreprise motive le choix du contrat offert. Les auteurs définissent par analyse les règles d'embauche et de congédiement des entreprises. Les paramètres du modèle sont estimés à l'aide de données canadiennes relatives au jumelage employeurs-salariés. La hausse des coûts de licenciement accroît l'inégalité des salaires et réduit le chômage. Cette montée de l'inégalité est causée par la présence d'une plus grande proportion de travailleurs temporaires et non par la majoration du surplus de rémunération octroyé aux travailleurs permanents.

Classification JEL : H29, J23, J38

Classification de la Banque : Marchés du travail; Production potentielle; Productivité 


\section{Introduction}

The existence of two-tiered labor markets in which workers are segmented by the degree of job protection they enjoy is typical in many OECD countries. Some workers, which one could label temporary (or fixed-term) workers, enjoy little or no protection. They are paid relatively low wages, they experience high turnover, and they transit among jobs at relatively high rates. Meanwhile, other workers enjoy positions where at dismissal the employer faces a firing tax or a statutory severance payment. These workers' jobs are more stable, they are less prone to being fired, and they are paid relatively higher wages. The menu and structure of available contracts is oftentimes given by an institutional background who seeks some policy objective. Workers and employers, however, can choose from that menu and agree on the type of relationship they want to enter.

This paper examines the conditions under which firms and workers decide whether to enter a permanent or a temporary relationship. Intuitively firms should always opt for offering workers the contract in which dismissal is free, not to have their hands tied in case the worker under-performs. We construct a theory, however, in which match-quality between a firm and a worker determines the type of contract chosen. By match quality we refer to the component of a worker's productivity that remains fixed as long as the firm and the worker do not separate and that is revealed at the time they meet. Firms offer workers with low match-quality a fixed-term contract, which can be terminated at no cost after one period and features a relatively low wage. If it is not terminated, the firm agrees to promote the worker and upgrade the contract into a permanent one, which features a higher wage and it is relatively protected by a firing tax. On the other hand, facing the risk of losing a good worker, firms find it optimal to offer high-quality matches a permanent contract. The firm ties its hands promising to pay the tax in case of termination and remunerating the worker with a higher wage. This higher wage induces the worker not to incur in costly on-thejob search. Endogenous destruction of matches, both permanent and temporary, arises from changes in a time-varying component of a worker's productivity: if these changes are negative enough, they force firms to end relationships. 
Our set-up is tractable enough to allow us to characterize three cut-off rules. First, we show that there exists a cut-off point in the distribution of match-specific shocks above which the firm offers a permanent contract, and below which the firm offers a temporary contract. There is also a cut-off point in the distribution of the time-varying component of productivity below which the relationship between a temporary worker and a firm ends and above which it continues. Finally, we show the existence of a cutoff point also in the distribution of the time-varying component of productivity below which the relationship between a permanent worker and a firm ends and above which it continues.

Naturally, workers stay longer in jobs for which they constitute a good-match. Permanent workers enjoy stability and higher pay. Temporary workers on the other hand experience high job-to-job transition rates in lower-paid jobs while they search for better opportunities. We emphasize that our theory delivers all of these results endogenously.

The paper does not examine the social or policy goals that lead some societies to establish firing costs or to regulate the relationships between workers and employers. Rather, we build a framework in which the menu of possible contracts is given by an institutional background that we do not model explicitly. We then use this framework to evaluate under what conditions employers and workers enter into temporary or permanent relationships. Not addressing the reasons for why governments introduce firing costs does not preclude us from making positive statements about the effects of changing those firing policies. This is precisely the goal of the second part of the paper: to quantitatively evaluate how the existence of firing costs helps shape the wage distribution. To perform this quantitative evaluation, we apply the theory to the economy of Canada. We choose to study the Canadian economy for three reasons. First, it has a rich enough dataset that allows us to distinguish workers by type of contract. Second, it is an economy with a significant amount of temporary workers who represent $14 \%$ of the total workforce. And third, Canada is one of the countries where the protection of permanent workers is weakest and an economy with minimal regulations of temporary workers (see Venn (2009)). These facts suggest that our theory, which emphasizes the choice of different contracts when match-quality differs, is perhaps more relevant 
for Canada than for other OECD countries (where firms and workers could have less freedom in which contract to choose). We use the Workplace and Employee Survey (WES), a matched employer-employee dataset, to link wages of workers to average labor productivities of the firms that employ them. This relationship, together with aggregate measures of turnover for permanent and temporary workers also obtained from the WES, forms the basis of our structural estimation procedure. We employ a simulated method of moments - indirect inference approach to structurally estimate the parameters of the model. The method uses a Markov Chain Monte Carlo algorithm proposed by Chernozhukov and Hong (2003) that overcomes computational difficulties often encountered in simulation-based estimation.

Having estimated the vector of structural parameters, we perform two experiments. In the first experiment, we use the model to assess the impact of firing costs on income inequality. We find that a $50 \%$ increase in the level of firing costs increases the standard deviation of the wage distribution by $20 \%$. This rise in inequality is due entirely to the increase in the fraction of temporary workers, which earn relatively lower wages. It is not due to an increase in the "permanent worker premium", the ratio of the wage a permanent worker earns relative to that a temporary worker. The fraction of temporary workers rises with firing costs because their relative price drops; permanent workers are more expensive since undoing a permanent match costs more. The wage premium changes little because on the one hand, employers want to hire high productivity permanent workers (to avoid having to hire them and pay the cost), but on the other hand it is more costly to destroy existing matches, even when workers have relatively low productivity. We also find that an increase in the firing costs lowers the degree of turnover (it lowers both destruction and creation rates) but it decreases the unemployment rate. The second experiment involves evaluating the welfare impact of introducing temporary contracts, starting from an economy with firing costs. Reforms of that type were introduced in some European countries in the 1980s and 1990s. ${ }^{1}$ The increase in welfare that results from such a policy change is caused by a decrease in the unemployment rate; some workers that would otherwise be unemployed are now employed as firms are more willing to post vacancies when temporary contracts are

\footnotetext{
${ }^{1}$ See Aguirregabiria and Alonso-Borrego (2009) for an empirical evaluation of the Spanish reform.
} 
permitted.

To the best of our knowledge, the literature lacks a theory of the existence of twotiered labor markets in which some some worker-firm pairs begin relationships on a temporary basis and other worker-firm pairs on a permanent basis. ${ }^{2}$ Again, by temporary and permanent relationships we have something specific in mind; namely contracts with different degrees of labor protection. Our study is not the first one that analyzes this question within a theoretical or quantitative framework, so by theory we mean not assuming an ex-ante segmentation of a labor market into temporary workers or permanent workers. This segmentation can occur for a variety of reasons: related to technology (e.g. assuming that workers under different contracts are different factors in the production function); due to preferences - assuming that workers value being under a permanent contract differently than being under a temporary contract), or that they are subject to different market frictions. There are several examples which feature such an assumption: Wasmer (1999), Alonso-Borrego, Galdón-Sánchez, and Fernández-Villaverde (2006), or Bentolila and Saint-Paul (1992). Blanchard and Landier (2002) take a slightly different route, associating temporary contracts with entry-level positions: a worker begins a relationship with a firm in a job with a low level of productivity. After some time, the worker reveals her true - perpetual - productivity level. ${ }^{3}$ If such level is high enough, the firm will retain the worker offering her a contract with job security. ${ }^{4}$ Cahuc and Postel-Vinay (2002) construct a search and matching framework to analyze the impact on several aggregates of changing firing costs. Their concept of temporary and permanent workers is similar to the one used here. However, it is the government that determines randomly what contracts are permanent and which are temporary. In other words, the fraction of temporary worker is itself a policy parameter. That model is unable to answer why these two contracts

\footnotetext{
${ }^{2}$ In the data, many workers that meet a firm for the first time are hired under a permanent contract.

${ }^{3}$ Faccini (2009) also motivates the existence of temporary contracts as a screening device. In his work, as in Blanchard and Landier, all relationships between workers and firms begin as temporary.

${ }^{4} \mathrm{~A}$ theory somewhat related to ours is due to Smith (2007). In a model with spatially segmented labor markets, it is costly for firms to re-visit a market to hire workers. This leads firms to hire for short periods of time if they expect the pool of workers to improve shortly and to hire for longer time periods if the quality of workers currently in a market is high. He equates a commitment by a firm to never revisit a market, as permanent duration employment. The route we take is to specify a set of contracts that resemble arrangements observed in many economies and ask when do employers and workers choose one arrangement over another.
} 
can co-exist in a world with ex-ante identical agents. The fraction of temporary workers ought to be an endogenous outcome and this endogeneity should be a necessary ingredient in any model that analyzes policies in dual labor markets. ${ }^{5}$

None of the studies mentioned in this summary of the literature is concerned with building a theory that explains why firms and workers begin both temporary and permanent relationships and analyzing policy changes once that framework has been built. We build such a theory, estimate its parameters and analyze its policy implications for wage inequality and welfare in subsequent sections.

\section{Economic Environment}

We assume a labor market populated by a unit mass of ex-ante identical workers who are endowed with one unit of time each period. These workers can be either employed or unemployed as a result of being fired and hired by a, potentially infinite, mass of firms. Workers search for jobs and each firm posts a vacancy with the hope of matching to a worker. The number of meetings between employers and workers is given by a matching technology that we specify below in detail. The main departure from standard search and matching models of labor markets (e.g. Mortensen and Pissarides (1994)) is our assumption that two types of contracts are available. The first type, which we label a permanent contract, has no predetermined length, but we maintain, however, the typical assumption of wage renegotiation at the beginning of each period. Separating from this kind of contract is costly. If a firm and a worker under a permanent contract separate, firms pay a firing tax $f$ that we assume is wasted. The second type of contract, a temporary contract, has a predetermined length of one period. Once that period is over, separating the match comes at no cost to the firm. If the firm and the worker decide to continue the relationship, the temporary contract is upgraded to a permanent one. This upgrade, which one could label a promotion, costs the firm a small fee $c$. Workers can incur $d$ units of utility to search for a job regardless of their

\footnotetext{
${ }^{5}$ There is a related branch of the literature that looks at the effect of increasing firing taxes on job creation, job destruction and productivity. An example is Hopenhayn and Rogerson (1993). They find large welfare losses of labor protection policies as they interfere with labor reallocation from high productivity firms to low productivity firms. Other examples would be Bentolila and Bertola (1990) or Álvarez and Veracierto $(2000,2006)$.
} 
employment status. Unemployed workers receive benefits $b$ for as long as they are unemployed, and the government finances this program by levying lump-sum taxes $\tau$ on workers and unemployed agents.

The production technology is the same for the two types of contracts. If a firm hires worker $i$, the match yields $z_{i}+y_{i, t}$ units of output in period $t$. The random variable $z$ represents match-quality: a time-invariant, while the match lasts, component of a worker's productivity which is revealed at the time of the meeting. In our theory, the degree of match-quality determines the type of contract agreed upon by the firm and the worker. This match-specific shock is drawn from a distribution $G(z)$. The time-varying component $y_{i, t}$ is drawn every period from a distribution $F(y)$ and it is responsible for endogenous separations. From our notation, it should be clear to the reader that both shocks are independent across agents and time. The supports of the distributions of both types of shocks are given by $\left[y_{\min }, y_{\max }\right]$ and $\left[z_{\min }, z_{\max }\right]$ and we will assume throughout that $y_{\min }<y_{\max }-c-f$.

A matching technology $B\left(v, N^{S}\right)$ determines the number of pairwise meetings between workers $\left(N^{S}\right)$ and employers (represented by the number of vacancies posted $v$ ). This technology displays constant returns to scale and implies a job-finding probability $\alpha^{w}(\theta)$ and a vacancy-filling probability $\alpha^{f}(\theta)$. which are both functions of the level of market tightness $\theta$. The job-finding and job-filling rates satisfy the following conditions: $\alpha^{w \prime}(\theta)>0, \alpha^{f \prime}(\theta)<0$ and $\alpha^{w}(\theta)=\theta \alpha^{f}(\theta)$. The tightness of the labor market is defined as the ratio of the number of vacancies to number of workers searching for jobs. Every time a firm decides to post a vacancy, it must pay a cost $k$ per vacancy posted. Finally, if a firm and a worker meet, $z$ is revealed and observed by both parties. The realization of $y$, however, occurs after the worker and the firm have agreed on a match and begun their relationship.

Let us first fix some additional notation:

- $Q$ : Value of a vacancy.

- $U$ : Value of being unemployed.

- $V^{P}$ : Value of being employed under a permanent contract. 
- $V^{R}$ : Value of being employed following promotion from a temporary position to a permanent one.

- $V^{T}$ : Value of being employed under a temporary contract.

- $J^{P}$ : Value of a filled job under a permanent contract.

- $J^{R}$ : Value of a filled job that in the previous period was temporary and has been converted to permanent.

- $J^{T}$ : Value of a filled job under a temporary contract.

It will be convenient to define by,

$$
A \equiv\left\{z \in\left[z_{\text {min }}, z_{\text {max }}\right] \mid E_{y} J^{P}(y, z) \geq E_{y} J^{T}(y, z)\right\}
$$

the set of realizations of $z$ for which the firm prefers to offer a permanent contract. For convenience, let $\mathbb{I}_{A}$ denote an indicator function defined as,

$$
\mathbb{I}_{A}= \begin{cases}1 & z \in A, \\ 0 & z \notin A .\end{cases}
$$

Similarly, denote a worker's search decision by an indicator $a$ as the following

$$
a= \begin{cases}1 & \text { search on-the-job, } \\ 0 & \text { do not search. }\end{cases}
$$

\subsection{Workers}

We now proceed to describe the value of being unemployed or employed under different contracts. The following equation states the value of being unemployed as the sum of the flow from home production (i.e., unemployment benefits) net of search costs and net of the lump-sum tax $b-d-\tau$ plus the discounted value of either being matched to an un-filled job, which happens with probability $\alpha^{w}(\theta)$, or remaining unemployed. 


$$
\begin{aligned}
U= & b-d-\tau+\beta\left(1-\alpha^{w}(\theta)\right) U \\
& +\beta \alpha^{w}(\theta) \int_{z_{\min }}^{z_{\max }}\left[\mathbb{I}_{A} E_{y} V^{P}(y, z)+\left(1-\mathbb{I}_{A}\right) E_{y} V^{T}(y, z)\right] d G(z),
\end{aligned}
$$

The value of being employed will depend on the type of contract agreed upon between the worker and the firm. In other words, the value of being employed under a permanent contract differs from being employed under a temporary contract. We begin by describing the evolution of $V^{P}$, the value being employed under a permanent contract, given by:

$$
V^{P}(y, z)=\max \left(V_{n}^{P}(y, z), V_{s}^{P}(y, z)\right),
$$

where $V_{n}^{P}$ is the value of not searching on-the-job, and $V_{s}^{P}$ is the value of searching on-the-job. Each of those two values satisfies the following Bellman equations,

$$
V_{n}^{P}(y, z)=w_{n}^{P}(y, z)-\tau+\beta \int_{y_{\min }}^{y_{\max }} \max \left(V^{P}(x, z), U\right) d F(x),
$$

and,

$$
\begin{aligned}
V_{s}^{P}(y, z)= & w_{s}^{P}(y, z)-d-\tau \\
& +\beta \alpha^{w}(\theta) \int_{z_{\min }}^{z_{\max }}\left[\mathbb{I}_{A} E_{y} V^{P}(y, x)+\left(1-\mathbb{I}_{A}\right) E_{y} V^{T}(y, x)\right] d G(x) \\
& +\beta\left(1-\alpha^{w}(\theta)\right) \int_{y_{\min }}^{y_{\max }} \max \left(V^{P}(x, z), U\right) d F(x) .
\end{aligned}
$$

If the worker finds it optimal not to search on the job, the flow value of being employed under a permanent contract is a wage $w_{n}^{P}(y, z)$; the discounted continuation value is the maximum of quitting and becoming unemployed, or remaining in the relationship. As the match-specific shock is time-invariant, only changes in time-varying productivity drive separations and changes in the wage. However, note that the firing decision occurs before production can even take place: the realization of $y$ that determines the wage is not the realization of $y$ that determines whether the relationship continues or not. In the case the worker decides to search while employed, see equation (3), she needs to pay a search cost $d$. In that case, the discounted continuation 
value differs from the no-search case and has two components. The first component describes the continuation value if the on-the-job search is unsuccessful. With probability $\left(1-\alpha^{w}(\theta)\right)$ the permanent worker does not find a job and the two remaining alternatives are obtaining a promotion and staying with the firm, or being dismissed and becoming unemployed. ${ }^{6}$

The worker employed under a temporary contract also decides whether to search on the job or not. When she searches, see equation (4) below, she earns $w_{s}^{T}(y, z)$ giving up $d$ units to finance her job search, which occurs at the end of the period. Again, the job finding probability the worker faces is the same as that faced by the unemployed and the permanent workers. Should the temporary worker not find a job, she faces the promotion decision after her new productivity level is revealed. She becomes unemployed if her realization of $y$ falls below a threshold to be defined later. Formally,

$$
\begin{aligned}
V_{s}^{T}(y, z)= & w_{s}^{T}(y, z)-d-\tau \\
& +\beta \alpha^{w}(\theta) \int_{z_{\min }}^{z_{\max }}\left[\mathbb{I}_{A} E_{y} V^{P}(y, x)+\left(1-\mathbb{I}_{A}\right) E_{y} V^{T}(y, x)\right] d G(x) \\
& +\beta\left(1-\alpha^{w}(\theta)\right) \int_{y_{\min }}^{y_{\max }} \max \left(V^{R}(x, z), U\right) d F(x) .
\end{aligned}
$$

If she does not search, the value of being a temporary worker is,

$$
V_{n}^{T}(y, z)=w_{n}^{T}(y, z)-\tau+\beta \int_{y_{\min }}^{y_{\max }} \max \left(V^{R}(x, z), U\right) d F(x) .
$$

A temporary worker's search decision sets $V^{T}(y, z)=\max \left(V_{n}^{T}(y, z), V_{s}^{T}(y, z)\right)$.

Let us define $V^{R}$, the value of working under a permanent contract for the first time; in other words, the value for a just-promoted worker. After earning a wage $w^{T}(y, z)$ for one period, conditional on her time-varying productivity not being too low, the temporary worker is "promoted". This promotion costs the firm $c$ and earns the worker a larger salary $w^{R}(y, z)$. This salary is not at the level of $w^{P}(y, z)$, as the

\footnotetext{
${ }^{6}$ We assume that workers who search on the job forgo the opportunity to return to their current employer if their job search is successful. By successful we mean that they find any job at all, and not necessarily a better job (a job with a higher $z$ ). While this assumption is un-realistic, due to random matching the problem becomes intractable if we assume workers can meet with a new firm, not match, and return to their current employer.
} 
firm has to face the $\operatorname{cost} c$, but it is higher than $w^{T}(y, z)$. The worker earns this higher salary for one period, and as long as she does not separate from the firm, she will earn $w^{P}(y, z)$ in subsequent periods. Consequently, the value of a just-promoted worker evolves as,

$$
V_{n}^{R}(y, z)=w_{n}^{R}(y, z)-\tau+\beta \int_{y_{\min }}^{y_{\max }} \max \left(V^{P}(x, z), U\right) d F(x),
$$

if the worker does not search, or

$$
\begin{aligned}
V_{s}^{R}(y, z)= & w_{s}^{R}(y, z)-d-\tau \\
& +\beta \alpha^{w}(\theta) \int_{z_{\min }}^{z_{\max }}\left[\mathbb{I}_{A} E_{y} V^{P}(y, x)+\left(1-\mathbb{I}_{A}\right) E_{y} V^{T}(y, x)\right] d G(x) \\
& +\beta\left(1-\alpha^{w}(\theta)\right) \int_{y_{\min }}^{y_{\max }} \max \left(V^{P}(x, z), U\right) d F(x),
\end{aligned}
$$

if she searches. Again, the just-promoted worker sets $V^{R}(y, z)=\max \left(V_{n}^{R}(y),, V_{s}^{R}(y, z)\right)$.

\subsection{Firms}

We now turn to define some recursive relationships that must hold between asset values of vacant jobs and filled jobs under different employment contracts. Let us begin by describing the law of motion for the asset value of a vacancy:

$$
\begin{aligned}
Q= & -k+\beta \alpha^{f}(\theta) \int_{z_{\min }}^{z_{\max }} \max \left(E_{y} J^{P}(y, z), E_{y} J^{T}(y, z)\right) d G(z) \\
& +\beta\left(1-\alpha^{f}(\theta)\right) Q,
\end{aligned}
$$

This equation simply states that the value of a vacant position is the expected payoff from that vacancy net of posting costs $k$. Both workers and firms discount expected payoffs with a factor $\beta$. With probability $\alpha^{f}(\theta)$, the vacant position gets matched to a worker. This vacancy can be turned into either a permanent job, or a temporary job, depending on the realization of the match-specific shock $z$. With probability $1-\alpha^{f}(\theta)$ 
the vacant position meets no worker and the continuation value for the firm is having that position vacant.

Regarding capital values of filled positions, the flow profit for a firm is given by the total productivity of the worker, $y+z$, net of the wage paid. And in the case of the just-promoted worker, net also of the promotion $\operatorname{cost} c$. Those capital values are given by,

$$
\begin{aligned}
J_{s}^{P}(y, z)= & y+z-w_{s}^{P}(y, z)+\beta \alpha^{w}(\theta) Q \\
+ & \beta\left(1-\alpha^{w}(\theta)\right) \int_{y_{\min }}^{y_{\max }} \max \left(J^{P}(x, z), Q-f\right) d F(x), \\
J_{s}^{R}(y, z)= & y+z-w^{R}(y, z)-c+\beta \alpha^{w}(\theta) Q \\
+ & \beta\left(1-\alpha^{w}(\theta)\right) \int_{y_{\min }}^{y_{\max }} \max \left(J^{P}(x, z), Q-f\right) d F(x), \\
J_{s}^{T}(y, z)= & y+z-w^{T}(y, z)+\beta \alpha^{w}(\theta) Q \\
& +\beta\left(1-\alpha^{w}(\theta)\right) \int_{y_{\min }}^{y_{\max }} \max \left(J^{R}(x, z), Q\right) d F(x) .
\end{aligned}
$$

Analogously, asset values of filled jobs when workers are not searching are given by

$$
\begin{aligned}
& J_{n}^{P}(y, z)=y+z-w_{n}^{P}(y, z)+\beta \int_{y_{\min }}^{y_{\max }} \max \left(J^{P}(x, z), Q-f\right) d F(x), \\
& J_{n}^{R}(y, z)=y+z-w_{n}^{R}(y, z)-c+\beta \int_{y_{\min }}^{y_{\max }} \max \left(J^{P}(x, z), Q-f\right) d F(x), \\
& J_{n}^{T}(y, z)=y+z-w_{n}^{T}(y, z)+\beta \int_{y_{\min }}^{y_{\max }} \max \left(J^{R}(x, z), Q\right) d F(x),
\end{aligned}
$$

After taking into account search decisions by workers summarized by the policy function $a$, the capital values of filled positions are then given by

$$
J^{i}(y, z)=a J_{s}^{i}(y, z)+(1-a) J_{n}^{i}(y, z)
$$

for $i \in\{P, R, T\}$. 


\section{Equilibrium}

To characterize the equilibrium, we first conjecture that there exists an interval $\left[d_{\min }, d_{\max }\right]$ for $d$ such that workers under permanent contracts decide not to search but workers under temporary contracts decide to search. Then given any $d \in\left[d_{\text {min }}, d_{\text {max }}\right]$ and the worker's optimal search decision under different types of contract, we determine the hiring and firing rules. These are summarized below in Propositions 1 and 2. In particular, we show that there exists a cut-off point $\bar{z}$ in the distribution of match-specific quality that determines the type of contract chosen. In other words, values of match quality below $\bar{z}$ will yield temporary contracts and values of match quality above $\bar{z}$ will yield permanent contracts. We also derive the firing rules which take the form of cut-off points $y^{P}(z)$ and $y^{R}(z)$ in the time-varying component of productivity. Draws of productivity below those two cut-off points destroy permanent and temporary relationships respectively. After having derived these hiring and firing rules, we show that there exists an interval $\left[d_{\text {min }}, d_{\text {max }}\right]$ for $d$ such that no worker has an incentive to deviate from the conjectured search decisions. In other words, for any value of $d$ inside that interval, permanent workers never choose to search and temporary workers always choose to search. This is shown by Proposition 3.

It will be convenient to re-write the value of a vacancy, using the definition of $\mathbb{I}_{A}$, as,

$$
\begin{aligned}
Q= & -k+\beta \alpha^{f}(\theta) \int_{z_{\min }}^{z_{\max }}\left[\mathbb{I}_{A} E_{y} J^{P}(y, z)+\left(1-\mathbb{I}_{A}\right) E_{y} J^{T}(y, z)\right] d G(z) \\
& +\beta\left(1-\alpha^{f}(\theta)\right) Q .
\end{aligned}
$$

So far we have been silent about wage determination. Following much of the search and matching literature we assume that upon meeting, firms and workers Nashbargain over the total surplus of the match. Clearly, the sizes of the surpluses will vary depending on whether the worker and the firm agree on a temporary contract or a permanent contract. We assume that workers and firms compute the sizes of the different surpluses and choose the largest one as long as it is positive. Since we have three 
different value functions for workers and firms, we have three different surpluses depending on the choices faced by employers and workers.

Denoting by $\phi$ the bargaining power of workers, the corresponding total surpluses for each type of contract are given by:

$$
\begin{aligned}
& S^{P}(y, z)=J^{P}(y, z)-(Q-f)+V^{P}(y, z)-U, \\
& S^{R}(y, z)=J^{R}(y, z)-Q+V^{R}(y, z)-U, \\
& S^{T}(y, z)=J^{T}(y, z)-Q+V^{T}(y, z)-U .
\end{aligned}
$$

As a result of the bargaining assumption, surpluses satisfy the following splitting rules:

$$
\begin{aligned}
& S^{P}(y, z)=\frac{J^{P}(y, z)-Q+f}{1-\phi}=\frac{V^{P}(y, z)-U}{\phi}, \\
& S^{R}(y, z)=\frac{J^{R}(y, z)-Q}{1-\phi}=\frac{V^{R}(y, z)-U}{\phi}, \\
& S^{T}(y, z)=\frac{J^{T}(y, z)-Q}{1-\phi}=\frac{V^{T}(y, z)-U}{\phi} .
\end{aligned}
$$

Free entry of firms takes place until any rents associated with vacancy creation are exhausted, which in turn implies an equilibrium value of a vacancy $Q$ equal to zero. Replacing $Q$ with its equilibrium value of zero in equation (15) results in the free-entry condition:

$$
k=\beta \alpha^{f}(\theta) \int_{z_{\min }}^{z_{\max }}\left[\mathbb{I}_{A} E_{y} J^{P}(y, z)+\left(1-\mathbb{I}_{A}\right) E_{y} J^{T}(y, z)\right] d G(z)
$$

The interpretation of this equation is that firms expect a per-vacancy-return equal to the right-hand-side of the expression to justify paying $k$. Using the surplus sharing rule in (16) and the free-entry condition, we can derive the following relationship:

$$
\int_{z_{\min }}^{z_{\max }}\left[\mathbb{I}_{A} E_{y} S^{P}(y, z)+\left(1-\mathbb{I}_{A}\right) E_{y} S^{T}(y, z)\right] d G(z)=\frac{k+\beta \alpha^{f}(\theta) \mu_{G}(A) f}{(1-\phi) \beta \alpha^{f}(\theta)},
$$


where $\mu_{G}(A)$ is the probability measure of $A$. Equation (17) states that the expected surplus, before firms and workers meet, is equal to the sum of two components. The first component, given by $\frac{k}{(1-\phi) \beta \alpha^{f}(\theta)}$, is the expected value of a filled job divided by $(1-\phi)$. This is another way of rewriting the surplus in a model with no firing costs and obtains in other models of search and matching in labor markets. The introduction of firing costs implies the total surplus needs to include the second component, $\frac{k+\beta \alpha^{f}(\theta) \mu_{G}(A) f}{(1-\phi) \beta \alpha^{f}(\theta)}$. This is the "compensation" to the firm for hiring a permanent worker, which occurs with probability $\alpha^{f}(\theta) \mu_{G}(A)$, and having to pay the firing cost $f$. Using this relationship together with equation (16) to substitute into equation (1), one can rewrite an expression for the value of being unemployed as,

$$
U=\frac{1}{1-\beta}\left\{b-d-\tau+\frac{\phi \alpha^{w}(\theta)\left(k+\beta \alpha^{f}(\theta) \mu_{G}(A) f\right)}{(1-\phi) \alpha^{f}(\theta)}\right\} .
$$

The value of unemployment can be decomposed into two components: a flow value represented by $b-d-\tau$ and an option value represented by the large fraction on the right-hand-side. Closer inspection facilitates the interpretation of that option value. Note that the expected surplus given by equation (17) equals this option value divided by $\phi \alpha^{w}(\theta)$. The worker, by being unemployed and searching, has the chance of finding a job, which happens with probability $\alpha^{w}(\theta)$, and obtaining a share $\phi$ of the expected surplus of that match.

Suppose that, for any $d \in\left[d_{\text {min }}, d_{\max }\right]$, the permanent worker does not search on the job while the temporary worker does. Given this conjecture, substituting equation (18) into equations (2), (4), (6), (11), (12) and (13) and using (16), yields the following convenient form of rewriting the surpluses under different contracts. 


$$
\begin{aligned}
S^{P}(y, z)= & y+z+\beta \int_{y_{\min }}^{y_{\max }} \max \left(S^{P}(x, z), 0\right) d F(x)+(1-\beta) f \\
& -(b-d)-\frac{\phi \alpha^{w}(\theta)\left(k+\beta \alpha^{f}(\theta) \mu_{G}(A) f\right)}{(1-\phi) \alpha^{f}(\theta)}, \\
S^{R}(y, z)= & y+z+\beta \int_{y_{\min }}^{y_{\max }} \max \left(S^{P}(x, z), 0\right) d F(x)-c-\beta f \\
& -(b-d)-\frac{\phi \alpha^{w}(\theta)\left(k+\beta \alpha^{f}(\theta) \mu_{G}(A) f\right)}{(1-\phi) \alpha^{f}(\theta)}, \\
S^{T}(y, z)= & y+z-b+\beta\left(1-\alpha^{w}(\theta)\right) \int_{y_{\min }}^{y_{\max }} \max \left(S^{R}(x, z), 0\right) d F(x)
\end{aligned}
$$

We begin by deriving the firing rules, by which we mean two threshold productivity values $y^{P}(z)$ and $y^{R}(z)$. These represent the lowest draws of time-varying productivity that imply continuing permanent $\left(y^{P}(z)\right)$ or temporary $\left(y^{R}(z)\right)$ relationships. Proposition 1 shows the existence of these values of $y$, conditional on the type of contract and the specific quality of the match, such that the relationship between a worker and a firm ends. Before stating that proposition we assume the following:

Assumption 1 Suppose $\theta$ is bounded and belongs to $\left[\theta_{\min }, \theta_{\max }\right]$, i.e., $0 \leq \alpha^{w}\left(\theta_{\min }\right)<$ $\alpha^{w}\left(\theta_{\max }\right) \leq 1$ and $0 \leq \alpha^{f}\left(\theta_{\max }\right)<\alpha^{f}\left(\theta_{\min }\right) \leq 1$. The following inequalities hold for exogenous parameters:

$$
\begin{array}{r}
y_{\max }+z_{\text {min }} \geq b-d_{\text {min }}+\frac{\phi}{1-\phi}\left(\theta_{\max } k+\beta \alpha^{w}\left(\theta_{\max }\right) f\right)-(1-\beta) f, \\
b-d_{\max }+\frac{\phi}{1-\phi} \theta_{\min } k-(1-\beta) f \geq y_{\min }+z_{\max }+\beta \int_{y_{\min }}^{y_{\max }}(1-F(x)) d x
\end{array}
$$

Assumption 2 In addition,

$$
y_{\max }+z_{\min }-c-f \geq b-d_{\min }+\frac{\phi}{1-\phi}\left(\theta_{\max } k+\beta \alpha^{w}\left(\theta_{\max }\right) f\right)-(1-\beta) f
$$

Proposition 1 Under Assumption 1, for any $d \in\left[d_{\min }, d_{\text {max }}\right]$ and any $z$, there exists an unique cut-off value $y^{P}(z) \in\left(y_{\min }, y_{\max }\right)$ and such that $S^{P}\left(y^{P}(z), z\right)=0$. If Assumption 2 also holds then the unique cut-off value $y^{R}(z) \in\left(y_{\min }, y_{\max }\right)$ exists where $S^{R}\left(y^{R}(z), z\right)=0$. 
The cut-off values solve the following equations: ${ }^{7}$

$$
\begin{aligned}
y^{P}+z+\beta \int_{y^{P}}^{y_{\max }}(1-F(x)) d x= & b-d-(1-\beta) f \\
& +\frac{\phi\left(\theta k+\beta \alpha^{w}(\theta) \mu_{G}(A) f\right)}{(1-\phi)}, \\
y^{P}+c+f= & y^{R} .
\end{aligned}
$$

Proposition 2 establishes the existence and uniqueness of a cut-off point $\bar{z}$ above which a firm and a worker begin a permanent relationship.

Proposition 2 There exists a unique cut-off value $\bar{z} \in\left[z_{\min }, z_{\max }\right]$ such that when $z>\bar{z}$ the firm only offers a permanent contract, while $z<\bar{z}$, only temporary contract is offered if the following conditions hold:

$$
d_{1} \equiv\left(y^{P}\right)^{-1}\left(y_{2} \mid z_{\max }, \theta_{\max }, \mu_{G}=1\right) \leq d \leq\left(y^{P}\right)^{-1}\left(y_{1} \mid z_{\min }, \theta_{\min }, \mu_{G}=0\right) \equiv d_{2}
$$

where

$$
\begin{array}{cc}
y_{1} \equiv & b-\frac{1}{1-\phi} f-z_{\text {min }} \\
y_{2} \equiv & \quad b-\frac{1}{1-\phi} f-z_{\max } \\
& -\beta\left(1-\alpha^{w}\left(\theta_{\min }\right)\right) \int_{y_{\min }}^{y_{\max }}[1-F(x)] d x
\end{array} .
$$

and $\left(y^{P}\right)^{-1}$ is the inverse function of $y^{P}$ defined in (25).

Having derived the firing and hiring rules, we now proceed to show the existence of an interval $\left[d_{\min }, d_{\max }\right]$ for $d$ such that no worker has an incentive to deviate from the assumed search policies. In other words, permanent workers have no incentive to search and temporary workers have the incentive to search. The following proposition establishes the existence of this interval.

Proposition 3 Given the hiring and firing rules described above, there exists an interval $\left[d_{\min }, d_{\max }\right]$ for the search cost parameter $d$ such that workers under a permanent contract have no incentive to search while workers under a temporary contract search on the job.

\footnotetext{
${ }^{7}$ Proofs for all propositions stated in the main body of the paper are relegated to an Appendix.
} 
The existence of the interval defined in Proposition 3 should be intuitive to the reader. If on-the-job search is too costly no employed worker would search irrespective of the type of contract. Likewise, if search costs little all workers might opt to seek alternative employment opportunities. However, it is also intuitive that for a given value of $d$, onthe-job search is more costly for workers under high-quality matches. The reason is that the "return" of searching on the job is lower for those high match-quality workers. These are precisely the workers hired under permanent contracts, and as a result there is a region for the on-the-job search cost $d$ such that permanent workers do not search but temporary workers do.

To obtain expressions for wages paid under different contracts we can substitute the value functions of workers and firms into the surplus sharing rule (16), which gives:

$$
\begin{aligned}
w^{P}(y, z)= & \phi(y+z)+(1-\phi)(b-d) \\
& +\phi\left[(1-\beta) f+\frac{\alpha^{w}(\theta)}{\alpha^{f}(\theta)}\left(k+\beta \alpha^{f}(\theta) \mu_{G}(A) f\right)\right], \\
w^{R}(y, z)= & w^{P}(y, z)-\phi(c+f), \\
w^{T}(y, z)= & \phi(y+z)+(1-\phi) b .
\end{aligned}
$$

Finally, we need to explicitly state how the stock of employment evolves over time. Let $u_{t}$ denote the measure of unemployment, and $n_{t}^{P}$ and $n_{t}^{T}$ be the measure of permanent workers and temporary workers. Let's begin by deriving the law of motion of the stock of permanent workers, which is given by the sum of three groups of workers. First, unemployed workers and temporary workers can search and match with other firms and become permanent workers. This happens with probability $\alpha^{w}\left(\theta_{t}\right) \mu_{G}(A)$. Second, after the realization of the aggregate shock, the permanent worker remains at the current job. The aggregate quantity of this case is $\int_{z_{\min }}^{z_{\max }} \mu_{F}\left(\left[y^{P}(z), y_{\max }\right]\right) d G(z) n_{t}^{P}$. Third, some of temporary workers who cannot find other jobs get promoted to permanent workers which adds to the aggregate employment pool for permanent workers by $\left(1-\alpha^{w}\left(\theta_{t}\right)\right) \int_{z_{\min }}^{\bar{z}} \mu_{F}\left(\left[y^{R}(z), y_{\max }\right]\right) d G(z) n_{t}^{T}$. Notice that $\mu_{G}(A)=1-G(\bar{z})$ and 
$\mu_{F}\left(\left[y, y_{\max }\right]\right)=1-F(y)$. The law of motion for permanent workers becomes:

$$
\begin{aligned}
n_{t+1}^{P}= & \left(u_{t}+n_{t}^{T}\right) \alpha^{w}\left(\theta_{t}\right)(1-G(\bar{z}))+\int_{z_{\min }}^{z_{\max }}\left[1-F\left(y^{P}(z)\right)\right] d G(z) n_{t}^{P} \\
& +\left(1-\alpha^{w}\left(\theta_{t}\right)\right) \frac{1}{G(\bar{z})} \int_{z_{\min }}^{\bar{z}}\left[1-F\left(y^{R}(z)\right)\right] d G(z) n_{t}^{T} .
\end{aligned}
$$

Unemployed workers and temporary workers who are unable to find high-quality matches, join the temporary worker pool the following period. Therefore the temporary workers evolve according to:

$$
n_{t+1}^{T}=\left(u_{t}+n_{t}^{T}\right) \alpha^{w}\left(\theta_{t}\right) G(\bar{z})
$$

Since the aggregate population is normalized to unity, the mass of unemployed workers is given by:

$$
u_{t}=1-n_{t}^{T}-n_{t}^{P} .
$$

The standard definition of market tightness is slightly modified to account for the onthe-job search activity of temporary workers:

$$
\theta_{t}=\frac{v_{t}}{u_{t}+n_{t}^{T}}
$$

\section{Partial Equilibrium Analysis}

To understand the intuition behind some of the results we show in the quantitative section, we perform here some comparative statics in "partial" equilibrium, by which we mean keeping $\theta$ constant. The goal is to understand how changes in selected variables impact the hiring and firing decisions.

Proposition 4 The hiring rule has the following properties:

1. $d \bar{z} / d f>0$,

2. $\left\{\begin{array}{ll}d \bar{z} / d \alpha^{w}<0 & \text { when } \phi<\bar{\phi} \\ d \bar{z} / d \alpha^{w}>0 & \text { when } \phi>\bar{\phi}\end{array}\right.$, 


\section{3. $d \bar{z} / d c<0$.}

The intuition behind Proposition 4 can be illustrated in Figures 1 to 3 . Figure 1 shows the effects of an increase in the firing cost $f$. This increase has two effects on the (net) value of a filled job. ${ }^{8}$ The direct effect causes a drop in the value of a permanent job because the firm has to pay more to separate from the worker. As a result the permanent contract curve shifts downward. An increase in $f$ also increases the job destruction rate of temporary workers by raising the threshold value $\bar{y}^{R}$, lowering the value of a temporary job. In equilibrium, the first effect dominates resulting in fewer permanent contracts.

Increasing the job finding probability has an ambiguous effect on the hiring decision because it depends on the worker's bargaining power. If it is easier for unemployed workers to find a job, the value of being unemployed increases because the unemployment spell is shortened. This lowers the match surplus since the worker's outside option rises. Therefore, the value of filled jobs falls and (both permanent and temporary) contract curves shifts outward. We call this the unemployment effect. However, there are two additional effects on temporary jobs. Since the temporary worker searches on-the-job, the higher job finding probability increases the chance that a temporary worker remains employed. Therefore, the match surplus rises due to the increase in the value of temporary employment. We call this effect the job continuation effect. For workers under temporary contract, these two effects exactly cancel out. On the other hand, the higher job finding probability causes more separations of temporary contracts. This so-called job turnover effect reduces the value of a temporary job which moves the temporary contract curve outward. If a worker has more bargaining power, then the unemployment effect dominates the job turnover effect. This case is depicted in Figure 1. However if the worker's bargaining power is small, the job turnover effect dominates the unemployment effect which leads to fewer temporary workers. The latter case is shown in Figure 2.

\footnotetext{
${ }^{8}$ The size of the surplus determines the type of contract chosen or whether matches continue or are destroyed. By Nash bargaining the value of a filled job is proportional to the total surplus, so it is sufficient to compare the changes in the values of filled jobs to determine the effects on the total surpluses.
} 
Finally, the effect of an increase in promotion costs is depicted in Figure 3. As promotion costs affect only the value of a temporary contract, an increase in $c$ reduces the incentive for promoting a temporary worker. As a result, the value of a temporary job decreases and the temporary contract curve shifts downward.

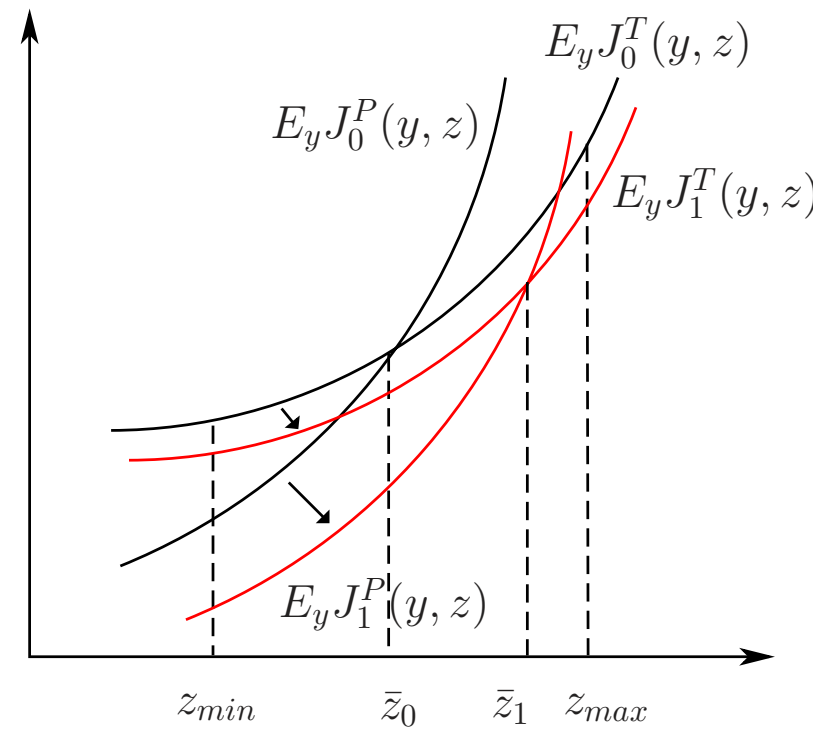

Figure 1: Effect of Changing the Firing Costs on Temporary Contracts

Proposition 5 If the firm has most of the bargaining power, the job destruction rule has the following properties:

1. $d y^{P} / d f<0$ and $d y^{R} / d f>0$,

2. $d y^{P} / d \alpha^{w}>0$ and $d y^{R} / d \alpha^{w}>0$.

3. $y^{P}$ is weakly increasing in $c$ and $d y^{R} / d c>0$.

The first part of Proposition 5 states that the firing cost has opposite effects on the separation of permanent jobs and temporary jobs. An increase in the firing cost decreases the firm's willingness to pay the cost to fire a permanent worker. However, it increases its willingness to separate from a temporary worker now, in order to avoid paying the higher firing cost in the future. The second part of the proposition results 


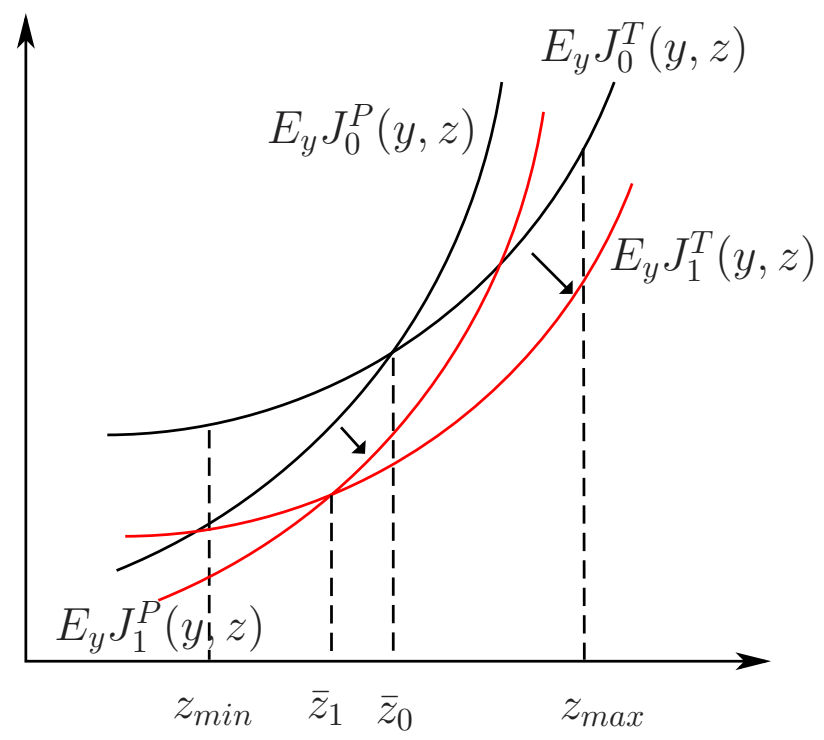

Figure 2: Effects of Changing the Job-Finding Probability on Temporary Contracts

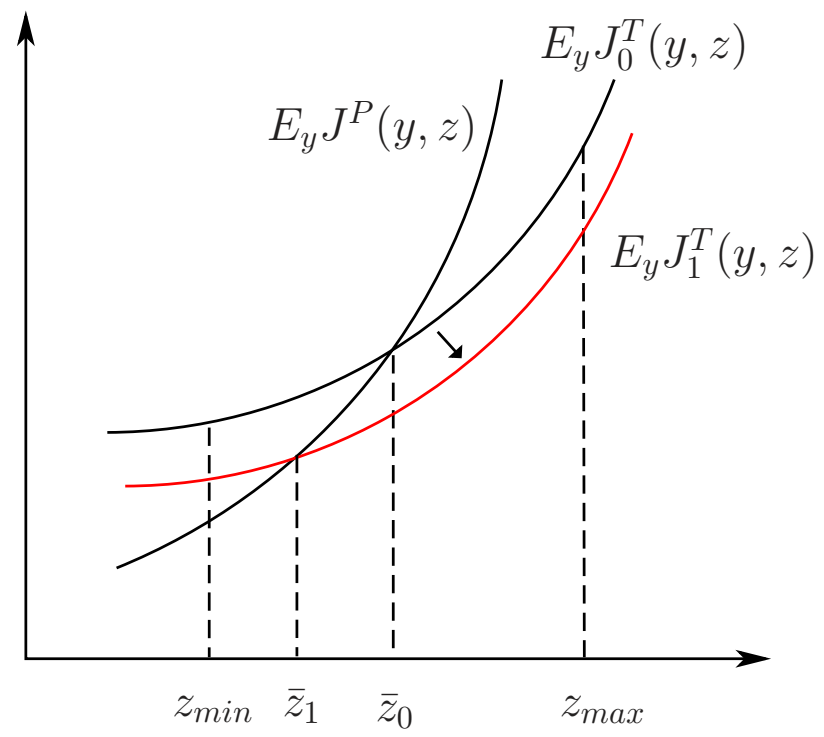

Figure 3: Effects of Changing the Promotion Costs on Temporary Contracts

mainly from a change in the hiring threshold. The last part is straightforward: an increase in promotion costs discourages the firm to retain the temporary worker.

Finally, we can take the hiring and firing decisions as given and ask how changes in the firing cost and promotion cost affect the job creation (vacancy posting) decision. 
The following proposition summarizes the results.

Proposition 6 Given the hiring and permanent job destruction rules, i.e. $\bar{z}$ and $y^{P}(z)$ are fixed, $d \theta / d f<0$ if $\beta$ is not too small and $d \theta / d c<0$.

The explanation of this proposition is that an increase in firing costs and promotion costs discourages the firm to post more vacancies by reducing the expected profits of jobs.

\section{Data}

To quantitatively explore the model, we use the Workplace and Employee Survey, a Canadian matched employer-employee dataset collected by Statistics Canada. It is an annual, longitudinal survey at the establishment level, targeting establishments in Canada that have paid employees in March, with the exceptions of those operating in the crop and animal production; fishing, hunting and trapping; households', religious organizations, and the government sectors. In 1999, it consisted of a sample of 6,322 establishments drawn from the Business Register maintained by Statistics Canada and the sample has been followed ever since. Every odd year the sample has been augmented with newborn establishments that have become part of the Business Register. The data are rich enough to allow us to distinguish employees by the type of contract they hold. However, only a sample of employees is surveyed from each establishment. ${ }^{9}$ The average number of employees in the sample is roughly 20,000 each year. Workers are followed for two years and provide responses on hours worked, earnings, job history, education, and demographic information. Firms provide information about hiring conditions of different workers, payroll and other compensation, vacancies, and separation of workers.

Given the theory laid out above, it is important that the definition of temporary worker in the data matches as close as possible the concept of a temporary worker in the model. In principle, it is unclear that all establishments share the idea of what a temporary worker is when they respond to the survey: it could be a seasonal worker, a

\footnotetext{
${ }^{9}$ All establishments with less than four employees are surveyed. In larger establishments, a sample of workers is surveyed, with a maximum of 24 employees per given establishment.
} 
fixed-term consultant hired for a project or a worker working under a contract with a set termination date. As a result, Statistics Canada implemented some methodological changes to be consistent in its definition of a temporary worker. This affected the incidence of temporary employment in the survey forcing us to use data only from 2001 onwards. The definition of temporary workers we use, it is of those receiving a T-4 slip from an employer but who have a set termination date. For instance, workers from temporary employment agents or other independent contractors are not included in our definition. With the use of this definition the fraction of temporary workers among all workers is $14 \%{ }^{10}$

Table 1 displays some descriptive statistics on workers' compensation by type of contract held. All quantities are in Canadian dollars and we use three different measures of compensation: total earnings reported by the employee, hourly wages with reported extra-earnings, and hourly wages without the reported extra earnings. According to the three measures, permanent workers earn more but they do work more as well. As a result, while total earnings of permanent workers are roughly double of those earned by temporary workers, when converted to hourly measures, that ratio drops to 1.14-1.15. The cross-sectional distribution of wages per hour has a larger variance in the case of temporary workers than of permanent workers. The standard deviation of permanent workers' hourly wages is about half of mean hourly wages. This ratio rises to $81 \%$ for temporary workers.

In Canada, job turnover is higher for temporary workers than for permanent workers, as extensively documented by Cao and Leung (2010). We reproduce some of their turnover statistics in Table 2. As it is typical, we measure turnover by comparing job creation and job destruction rates. If we denote by $E M P_{t, i}$ the total level of employment at time $t$ at establishment $i$, the creation and destruction rates between periods $t$ and $t+1$ are calculated as:

$$
\text { Creation }=\sum_{i} \frac{E m p_{t+1, i}-E m p_{t, i}}{0.5\left(E m p_{t+1}+E m p_{t}\right)}
$$

\footnotetext{
${ }^{10}$ There is temporary employment in all demographic groups, though younger workers are more likely to hold a temporary job. Our model is consistent with this data fact by allowing for the promotion of a temporary worker who can be a young worker.
} 
Table 1: Worker's Compensation by Type of Contract

\begin{tabular}{lcc}
\hline & & \\
\hline & Mean & Standard Deviation \\
\hline Permanent & & \\
\hline & & \\
Real Earnings & & \\
Real Hourly Wage (No Extra) & $\$ 21,847$ & $\$ 33,525$ \\
Real Hourly Wage & $\$ 22.57$ & $\$ 11.75$ \\
\hline & & \\
Temporary & & \\
\hline & & \\
Real Earnings & & \\
Real Hourly Wage (No Extra) & $\$ 18.87$ & $\$ 15.40$ \\
Real Hourly Wage & $\$ 19.54$ & $\$ 18.85$ \\
\hline & & \\
\hline
\end{tabular}

if $E m p_{t+1, i}-E m p_{t, i}>0$ and 0 otherwise. And,

$$
\text { Destruction }=\sum_{i} \frac{\left|E m p_{t+1, i}-E m p_{t, i}\right|}{0.5\left(E m p_{t+1}+E m p_{t}\right)}
$$

if $E m p_{t+1, i}-E m p_{t, i}<0$ and 0 otherwise.

Given the emphasis of our work on a labor market segmented by temporary and permanent workers, we use the previous expressions to provide measures of job destruction and creation by the type of contract held. However, we measure creation and destruction of temporary (or permanent) workers relative to the average total employment level. In other words, we measure the change in the stock of workers by contract type relative to the stock of total employment. These rates are given on the first two lines of Table 2. The job destruction rates are $6.4 \%$ for permanent workers and $6.2 \%$ for temporary workers. The creation rates are $8.1 \%$ and $5.3 \%$. As the fraction of temporary workers is only $14 \%$ of the workforce, these rates point to a much higher degree of turnover for temporary workers. 
Table 2: Job Creation and Job Destruction (\%)

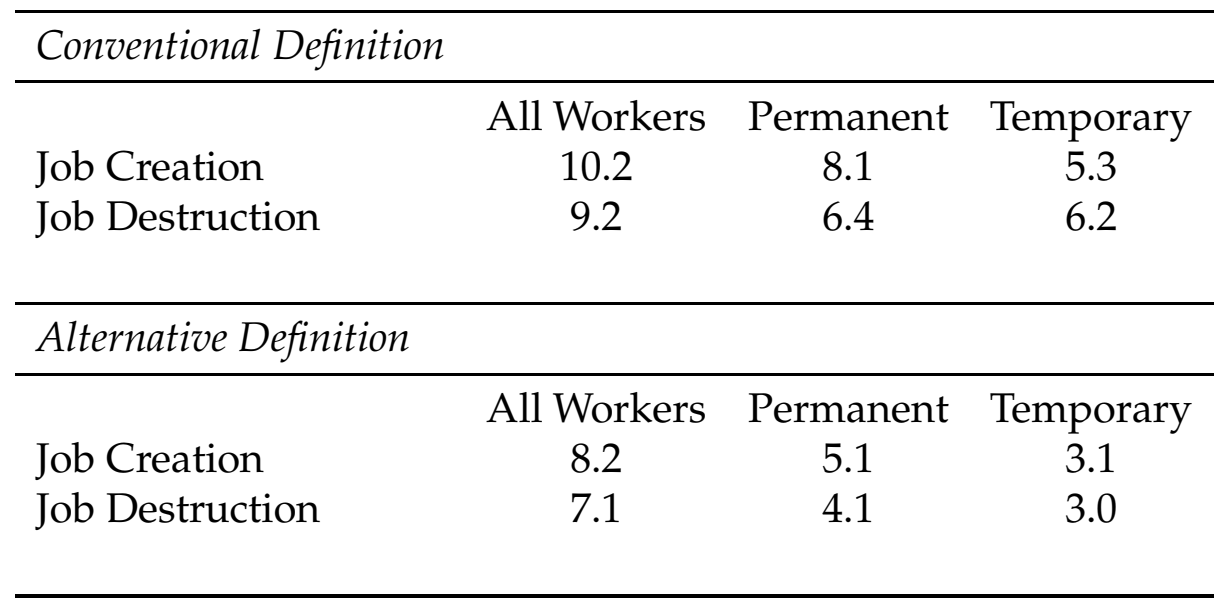

The reader might have noticed that the sum of the destruction rates for temporary and permanent workers is not equal to the destruction rate for all workers. The same can be said for the creation rate. The reason is that establishments can change the number of temporary and permanent workers without altering the stock of all workers. If we restrict the sample to those establishments that increase or decrease the stock of both permanent and temporary workers, the rates for all workers are the sum of the rates of the two types of workers. These measures are reported in Table 2 under the "Alternative Definition" label. Turnover decreases under this alternative definition, with creation and destruction rates for all workers that are $2 \%$ lower than using the conventional definition. The total job creation rate is $8.2 \%$ and the job destruction rate is $7.1 \%$.

\section{Model Estimation}

Our goal is to use our theory to understand patterns of inequality as they relate to employment contracts. More specifically, we want to assess how changes in firing policies affect inequality in wages and this goal demands our theory to be parameterized in a reasonable manner. This section describes the mapping between theory and data, goes over some technicalities of this mapping and shows its results. 
Obtaining a solution for the model requires specifying parametric distributions for $G(z)$ and $F(y) .{ }^{11}$ We assume that $y$ is drawn from a normal distribution and $z$ from a uniform distribution. In the model the overall scale of the economy is indeterminate and shifts in the mean of $y$ plus $z$ have no impact. Consequently, we normalize the mean of $y$ plus $z$ to one, reducing the dimension of the parameter vector of interest. One needs a functional form for the matching technology as well. Denote by $B$ the level of matches given vacancies $v$ and searching workers $N^{S}=n^{T}+u$. Note that we have already excluded the mass of permanent workers from the pool of searching workers. Given that our data set does not provide information about on the job behavior (or job-to-job transitions), we fix $d$ to a value of zero and check whether the sufficient conditions of Proposition 3 hold. With this fixed value for $d$ we estimate the remaining parameters of interest. We give more detail a few paragraphs below on how we perform that estimation. But first, we assume the matching function to be of the form,

$$
B\left(v, N^{S}\right)=\frac{v N^{S}}{\left(v^{\tau}+N^{S \zeta}\right)^{\frac{1}{\zeta}}} .
$$

This choice of technology for the matching process implies the following job-finding and job-filling rates, where, again we define $\theta=v / N^{S}$ :

$$
\alpha^{w}(\theta)=\frac{\theta}{\left(1+\theta^{\tilde{\zeta}}\right)^{\frac{1}{\xi}}}
$$

and

$$
\alpha^{f}(\theta)=\frac{1}{\left(1+\theta^{\xi}\right)^{\frac{1}{\xi}}} .
$$

Having specified parametric forms for $G, F$, and the matching technology we are now ready to describe our procedure in detail. Let $\gamma=\left(f, b, \phi, \xi, k, \mu_{y}, \sigma_{z}, \sigma_{y}\right)$ be the vector of structural parameters we need to estimate where $\mu_{x}$ and $\sigma_{x}$ denote the mean and the standard deviation for a random variable $x .{ }^{12}$ The literature estimating search

\footnotetext{
${ }^{11}$ The reader can find much technical detail about our solution and estimation algorithms in a Technical Appendix

${ }^{12}$ Parameters $c, \beta$, and $\mu_{z}$, should in principle be included in the vector $\gamma$. We fix $\beta$ to be 0.96 and $c$ to be $1 \%$ of the firing cost $f$. The standard deviation of $z$ is given by the normalization that $E(y)+E(z)=1$.
} 
models is large and much of it has followed full-information estimation methodologies, maximizing a likelihood function of histories of workers. ${ }^{13}$ These workers face exogenous arrival rates of job offers (both on and off-the-job) and choose to accept or reject such offers. Parameters maximize the likelihood of observing workers' histories conditional on the model's decision rules. In this paper, we depart from this literature by choosing a partial information approach to estimating our model. Our reason is twofold. First, our search model is an equilibrium one; the arrival rates of job offers are the result of aggregate behavior from the part of consumers and firms. Second, the lack of a panel dimension of the WES does not allow us to perform a maximum likelihood estimation. For these reasons, we take a partial-information route and estimate the model by combining indirect inference and simulated method of moments.

The first step involves choosing a set of empirical moments; set of dimension at least as large as the parameter vector of interest. We estimate the parameters by minimizing a quadratic function of the deviations of those empirical moments from their modelsimulated counterparts. Formally,

$$
\hat{\gamma}=\underset{\gamma}{\operatorname{argmin}} M\left(\gamma, \mathbf{Y}_{T}\right)^{\prime} W\left(\gamma, \mathbf{Y}_{T}\right) M\left(\gamma, \mathbf{Y}_{T}\right)
$$

where $\hat{\gamma}$ denotes the point estimate for $\gamma, W$ is a weighting matrix, and $M$ is a column vector whose $k$-th element denotes a deviation of an empirical moment and a model-simulated moment. The vector $\mathbf{Y}_{T}$ describes time series data - of length $T$ - from which we compute the empirical moments. The above expression should be familiar to readers, as it is a standard statistical criterion function in the method-of-moments or GMM literatures. Traditional estimation techniques rely on minimizing the criterion function (36) and using the Hessian matrix evaluated at the minimized value to compute standard errors. In many instances equation (36) is non-smooth, locally flat, and have several local minima. For these reasons, we use the quasi-Bayesian Laplace Type Estimator (LTE) proposed by Chernozhukov and Hong (2003). They show that under some technical assumptions, a transformation of (36) is a proper density function

\footnotetext{
${ }^{13}$ The list is far from being exhaustive but it includes Cahuc et al. (2006), Finn and Mabli (2009), Bontemps et al. (1999), Eckstein and Wolpin (1990). The reader is referred to Eckstein and Van den Berg (2007) for a survey of the literature that includes many more examples.
} 
(in their language, a quasi-posterior density function) As a result, they show how moments of interest can be computed using using Markov Chain Monte Carlo (MCMC) techniques by sampling from that quasi-posterior density. We describe our estimation technique in more detail in the technical appendix, but MCMC essentially amounts to constructing a Markov chain that converges to the density function implied by a transformation of (36). Draws from that Markov Chain are draws from the quasi-posterior, and as a result, moments of the parameter vector such as means, standard deviations, or othe quantities of interest are readily available. An important aspect of the estimation procedure is the choice of the weighting matrix $W$. We post-pone a description of how we weight the different moments and we now turn to describe the moments themselves.

Indirect inference involves positing an auxiliary - reduced-form - model which links actual data and model-simulated data. Given our focus on wage inequality, the auxiliary model we choose is a wage regression that links wages, productivity, and the type of contract held. Before being more specific about this regression let us first discuss an identification assumption needed to estimate it. An important element in our model's solution are wages by type of contract which are given by equations (29)(31). Irrespective of the type of contract wages are always a function of a worker's productivity $y+z$. In the data, such productivity is unobserved; one observes an establishment's total productivity or the productivity for the entire sample. To overcome this difficulty we assume that the time-varying component of productivity $y$ is firm or establishment-specific. Consequently, differences among workers' wages within a firm will be the result of working under a different contract or of having a different match-specific quality. We then posit that the $(\log )$ wage of worker $i$ of firm $j$ at time $t$ is given by:

$$
\log \left(w_{i j t}\right)=\beta+\beta_{A L P} \log \left(A L P_{j t}\right)+\beta_{\text {Type }} \chi_{i j t}+\epsilon_{i j t}
$$

where $A L P_{j t}$ is an establishment's average labor productivity - output divided by total hours - and $\chi_{i j t}$ is an indicator variable describing a worker's temporary status. This is the equation we estimate from the data. ${ }^{14} \mathrm{~A}$ panel of values for $A L P_{j t}$ is easy to

\footnotetext{
${ }^{14}$ We take logarithms for wages and $A L P P_{j t}$ as our model is stationary and displays no productivity
} 
obtain, as we have observations on the number of workers and the amount of output per establishment. Note that variations over time in $A L P_{j t}$ arise from changes in the time-varying productivity shock but also from the matches and separations that occur within a establishment over time. If as a result of turnover within a establishment, the mix of workers changes- there are more temporary workers in some year, for instancethe average worker productivity will change, even without a change in $y_{j t}$. Let us now describe what is the analogous equation to (37) we estimate in our model-simulated data. Our theory is silent about firms or establishments; there are only matches of which one can reasonably speak. Note, however, that $A L P_{j t}$ is the sum of the timevarying component $y_{j t}$ plus an expectation of the match-specific productivity $z$ at time $t$ - assuming a large number of workers per establishment. Hence, we simulate a large number of values of $y, z$, and wages by contract type and regress the logarithm of wages on a constant, the logarithm of the sum of $y$ and the mean simulated $z$ and the contract type. Disturbances in this regression will be interpreted as deviations of the match-specific quality for a given match relative to its mean match-specific value (plus some small degree of simulation error).

Our sample of the WES data-set covers the years 2001 to 2006. We estimate equation (37) for each year which yields a series of estimates $\left(\beta, \beta_{A L P}, \beta_{\text {Type }}, \sigma_{\epsilon}\right)$. Returning to our criterion function (36), the first two moments we choose to match are the timeseries averages of the coefficients $\beta_{A L P}$ and $\beta_{\text {Type }}$. Table 3 summarizes the vector of all moments (a total of 13), which includes time-series averages of job-creation and jobdestruction (for all workers, JD and JC; and for permanent and temporary workers, $J C_{P}, J D_{P}, J C_{T}$, and $\left.J D_{T}\right)^{15}$, the fraction of temporary workers $\left(\frac{n^{T}}{1-u}\right)$, the job-finding probability $\left(\alpha^{w}\right)$, and the ratio of wages of permanent workers to those of temporary workers $\left(\frac{w^{P}}{w^{T}}\right)$, the unemployment rate $(u)$, and the average of the fraction of the firing costs relative to the wage of a permanent worker $\left(\frac{f}{w^{P}}\right){ }^{16}$

The deviations of the empirical averages from their model counterparts comprise the vector $M$. Following much of the GMM literature, we weight elements of $M$ accord-

growth.

${ }^{15}$ We follow the "Conventional Definition" (see Table 2) for computing these destruction and creation rates. In the Appendix the reader will find detailed expressions that show how we calculate them.

${ }^{16}$ We thank M. Zhang for sharing her data on the Canadian job-finding rate used in Zhang (2008). 
Table 3: Statistical Properties: Empirical Moments (2001-2006)

\begin{tabular}{lcc}
\hline Series & Mean & $\begin{array}{c}\text { Standard } \\
\text { Deviation }\end{array}$ \\
\hline$J D$ & 0.092 & 0.025 \\
$J C$ & 0.102 & 0.018 \\
$J D_{P}$ & 0.064 & 0.020 \\
$J D_{T}$ & 0.062 & 0.015 \\
$J C_{P}$ & 0.081 & 0.021 \\
$J C_{T}$ & 0.053 & 0.009 \\
$n^{T} /(1-u)$ & 0.140 & 0.040 \\
$\alpha^{w}$ & 0.919 & 0.004 \\
$f / w^{P}$ & 0.182 & 0.002 \\
$w^{P} / w^{T}$ & 1.140 & 0.034 \\
$u$ & 0.071 & 0.004 \\
$\beta A P L$ & 0.159 & 0.013 \\
$\beta_{\text {Type }}$ & 0.193 & 0.019 \\
\hline
\end{tabular}

ing to the inverse of the covariance matrix of the deviations of the time series shown in Table 3 from their model equivalents.

\section{Results}

Table 4 shows the estimated parameter values along with their standard errors. The point estimates are the quasi-posterior means and the standard errors are the quasiposterior standard deviations. ${ }^{17}$ We estimate a bargaining power of workers $\phi$ equal to 0.62 . This value is about the same magnitude as those that are calibrated, but larger than previously estimated values such as Cahuc et al.'s (2006), which is very close to zero. The estimation yields distributions for $y$ and $z$ whose means are far apart. Recall that $E(y)+E(z)=1$ but $E(y)$ is larger than 4 . The theory imposes several restrictions on the parameter vector beyond the usual ones (e.g. $\phi \in(0,1)$ ). In particular, we impose the restrictions over the parameter space described in Assumptions 1 and 2, and also those sufficient restrictions for the results we present in Proposition 2 to be

\footnotetext{
${ }^{17}$ These results are based on 4,000 draws of the Markov chain.
} 
Table 4: Posterior Moments

\begin{tabular}{rrr}
\hline & Mean & Std. Dev \\
\hline$f$ & 0.185 & 0.002 \\
$k$ & 0.068 & 0.013 \\
$b$ & 0.713 & 0.017 \\
$\phi$ & 0.620 & 0.002 \\
$\xi$ & 4.336 & 0.019 \\
$\sigma_{z}$ & 0.025 & 0.006 \\
$\mu_{y}$ & 4.160 & 0.012 \\
$\sigma_{y}$ & 0.717 & 0.006 \\
\hline
\end{tabular}

valid. It is not possible, however, to satisfy the restrictions described in the proof for Proposition 3, that are sufficient to establish the existence of the interval $\left[d_{\min }, d_{\max }\right]$ such that permanent workers do not search and temporary workers do. ${ }^{18}$

These estimated parameters imply moments that we report on the first column of Table $5 .{ }^{19}$ The second column of the table reports the equivalent empirical moments. The fit is satisfactory and only one moment is significantly off its empirical value: the fraction of temporary workers. The reader should bear in mind that the fraction of temporary workers from the workers' survey is smaller than the number reported in the establishment survey. In the latter the number is the $14 \%$ we use as the actual empirical value, but in the workers' survey the number is much smaller; about $5 \%$. The unemployment rate is perhaps another moment in which the model does not give a good fit. It is somewhat difficult to get it to be below $10 \%$. All in all, we find these results remarkable for two reasons. First, because of how parsimonious and stylized our theory is. Two, because we are imposing tight restrictions on the parameter space, restrictions that are present in the theory but that one could relax by means of measurement error or stochastic disturbances of a different nature. We choose not to, and except for the restriction on the on-the-job search policies, the theory seems to be consistent with those restrictions by providing a good fit.

\footnotetext{
${ }^{18}$ We were unable to satisfy those restrictions even for values of $d$ larger than zero. The results shown correspond to the case $d=0$.

${ }^{19}$ We performed an alternative estimation restricting our data to firms that were in the sample for the entire time (in other words, a balanced panel of firms). Parameters estimated with this alternative dataset were similar to estimates shown here. These alternative results are available upon request.
} 


\subsection{Firing Costs and Wage Inequality}

We perform the experiment of increasing firing costs by $50 \%$ from the estimated value of $f=0.185$. Table 6 reports the result from this experiment. The first and the last column of that table show the same numbers as Table 5 . The middle column shows the results for the economy with the $50 \%$ increase in the level of firing costs. Increasing $f$ has a modest effect in all moments except obviously the share of wages that the firm has to pays as a firing tax.

As intuition would suggest, creation and destruction of permanent matches drop. The function $Y^{P}(z)$ shifts downward (i.e. falls for every value of $z$ ) but the shift is more pronounced for higher values of $z$. The creation rate of permanent jobs drops by about $30 \%$ and the destruction rate by a bit less. ${ }^{20}$ Since the majority of workers are employed under permanent contracts, when aggregating across both types of workers creation and destruction rates fall. However, the destruction rate falls less than the creation rate, contributing to the rise in employment and the fall in the unemployment rate. Not surprisingly, the rise in employment is entirely due to the rise in the number of temporary workers, as they are relatively cheap. The destruction rate of temporary workers rises because fewer of them obtain promotions. Perhaps surprisingly, the creation rate of temporary jobs falls. The explanation for this fall is clear once one recalls the definition of that creation rate. It is given by $\alpha^{w}(\theta)(1-G(\bar{z})) u /\left(n^{T}+n^{P}\right)$; on net, the only way to create a temporary job is for an unemployed person to find a temporary job. However, our convention is to compute these newly created jobs as a fraction of total employment. The stock of employed people rises substantially, contributing to the fall in the creation rate.

Increasing the level of $f$ has no discernible effect on the wage premium permanent workers earn. The rise in $f$, which increases that wage premium, is offset by other factors, such as the drop in the job-finding probability, which decreases the premium. On net, the ratio of permanent to temporary wages barely decreases.

\footnotetext{
${ }^{20}$ Given that $Y^{P}(z)$ drops more for larger values of $z$, the increase in firing costs is not large enough to completely shift the $Y^{R}(z)$ schedule. It turns out that the latter tilts clockwise. Recall that $Y^{R}=$ $y^{P}+f+c$. If the drop in $Y^{P}$ is large enough for large values of $z$, adding the new level of firing costs will not be enough to shift upwards $Y^{R}(z)$ above its previous value, for all values of $z$. The new value for $Y^{R}$ after increasing $f$ by $50 \%$ is higher for low values of $z$ but lower for higher values of $z$. However, since low values of $z$ characterize temporary contracts the destruction rate of temporary workers increases.
} 
Table 5: Moments: Models vs. Data

\begin{tabular}{rrr}
\hline & Model & Data \\
\hline$J D$ & 0.106 & 0.092 \\
$J C$ & 0.110 & 0.102 \\
$J D_{P}$ & 0.105 & 0.064 \\
$J D_{T}$ & 0.041 & 0.062 \\
$C_{P}$ & 0.105 & 0.081 \\
$J C_{T}$ & 0.068 & 0.053 \\
$n^{T} /(1-u)$ & 0.064 & 0.140 \\
$\alpha^{w}(\theta)$ & 0.920 & 0.919 \\
$f / w^{P}$ & 0.182 & 0.182 \\
$w^{P} / w^{T}$ & 1.123 & 1.140 \\
$u$ & 0.106 & 0.071 \\
$\beta_{A P L}$ & 0.174 & 0.159 \\
$\beta_{\text {Type }}$ & 0.132 & 0.193 \\
\hline
\end{tabular}

Table 6: Effects of an Increase in Firing Costs $(f)$

\begin{tabular}{lccc}
\hline & $f=0.185$ & $f=1.5^{*} 0.185$ & Data \\
\hline$J D$ & 0.102 & 0.077 & 0.092 \\
$J D_{P}$ & 0.102 & 0.076 & 0.064 \\
$J D_{T}$ & 0.040 & 0.047 & 0.062 \\
$J C$ & 0.105 & 0.081 & 0.102 \\
$J C_{P}$ & 0.101 & 0.072 & 0.081 \\
$J C_{T}$ & 0.065 & 0.034 & 0.053 \\
$\frac{n^{T}}{n^{T}+n^{P}}$ & 0.062 & 0.098 & 0.140 \\
$\alpha(\theta)$ & 0.922 & 0.899 & 0.919 \\
$\frac{f}{w}$ & 0.182 & 0.274 & 0.182 \\
$\beta_{1}$ & 0.166 & 0.261 & 0.159 \\
$\beta_{2}$ & 0.207 & 0.126 & 0.193 \\
$u$ & 0.103 & 0.083 & 0.071 \\
$\frac{w^{P}}{w^{T}}$ & 1.139 & 1.136 & 1.140 \\
\hline & & & \\
\hline
\end{tabular}


What are the implications of these changes for the shape of the wage distribution? Figure 4 shows the wage distribution for the three cases discussed. The blue (solid) line represents the density function of wages (using standard kernel-smoothing methods) when the parameters are set to their quasi-posterior means. If we increase the level of firing costs by $50 \%$, the result is the red (dashed-dotted) line: lower mean wages, because of the larger fraction of temporary workers, and considerably larger inequality. ${ }^{21}$

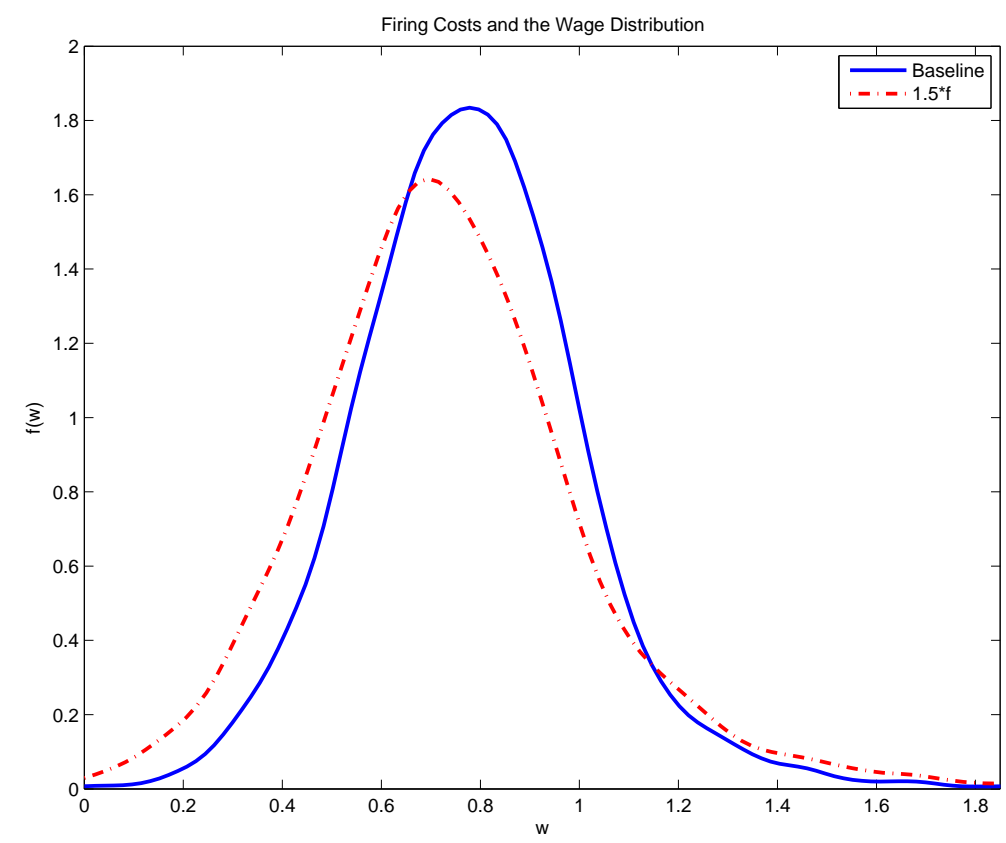

Figure 4: Wage distributions for different levels of firing costs.

\subsection{The Welfare Implications of Temporary Contracts}

We now provide some calculations of the changes in welfare that result from the introduction of temporary contracts in economies where existing workers are protected by firing costs. We do so by performing the following computational experiment. Given the estimated parameters above (the baseline case), we force $\bar{z}$ to drop to a level in

\footnotetext{
${ }^{21}$ Inequality measured using the standard deviation rises by $21 \%$ and the mean of wages falls by roughly $6 \%$.
} 
Table 7: Temporary Contracts: Welfare Evaluation

\begin{tabular}{rrrr}
\hline Model & $u$ & $\theta$ & $\mathcal{W}$ \\
\hline Baseline & 0.106 & 1.20 & 24.41 \\
No Temp. & 0.123 & 0.76 & 21.37 \\
\hline
\end{tabular}

which the fraction of temporary workers is zero. ${ }^{22}$ The goal is to compare welfare changes from the baseline economy to this second economy in which the fraction of temporary workers is zero. As a measure of welfare we compute,

$$
\mathcal{W}=\frac{1}{1-\beta}\left\{n^{T} E\{(y+z) \mid z \leqq \bar{z}\}+n^{P} E(y+z)-k v-n^{P} f \int_{z_{\min }}^{z_{\max }} F\left(y^{P}(z)\right) d G(z)\right\}
$$

Note that in this expression we have equated the aggregate unemployment benefits payment $b u$ to taxes levied $\tau$. Hence, the welfare of unemployed agents does not appear explicitly but it is taken into account. As the first row, third column, of Table 7 shows, the welfare of the baseline economy of the baseline economy is 24.41 . This economy features an unemployment rate of $10.6 \%$ and an equilibrium value of $\theta$ of 1.20. When the value of $\bar{z}$ is forced to be equal to $z_{\min }$, the welfare drops to a value of 21.37 , as the second row of the table indicates. ${ }^{23}$ This decrease of about $12 \%$ results from the higher unemployment rate $(12.3 \%$ vs. $10.6 \%)$, which in turn results from the much lower level of vacancies posted by firms. This can be seen from the large drop in $\theta$ (from 1.20 to 0.76 ). ${ }^{24}$

\section{Concluding Remarks}

This study provides a theory of the co-existence of labor contracts with different firing conditions. Consistent with empirical evidence that points to employers choosing among contracts with different degrees of labor protection, firms here choose to offer

\footnotetext{
${ }^{22}$ We check that for these lower levels of $\bar{z}$ workers and firms still want to match. That is, $E_{y} S^{P}(y, \bar{z})>$ 0 .

${ }^{23}$ It is important to emphasize that we do not change any of the elements of the vector $\gamma$ to achieve $\bar{z}=z_{\text {min }}$.

${ }^{24}$ Indeed, the vacancy filling rate increases from 0.76 in the baseline case to 0.94 in the economy with no temporary workers.
} 
ex-ante identical workers different contracts, and as a result, different wages. The reason is match-quality that varies across worker-firm pairs and that is revealed at the moment firms and workers meet. Firms offer permanent contracts to "good" matches, as they risk losing the worker should they offer them a temporary contract. This risk results from the different on-the-job search behavior by the two types of workers: in equilibrium temporary workers search while permanent workers do not. Not-so-good matches are given a temporary contract under which they work for a lower wage. After one period, temporary workers have to be dismissed or promoted to permanent status.

The existence of search and matching frictions implies that workers might work temporarily in jobs with an inferior match quality, before transferring to better, and more stable, matches. Our assumption of including a time-varying component in the total productivity of a worker allows our environment to generate endogenous destruction rates that differ by type of contract. Our environment is simple enough to deliver several analytical results regarding cut-off rules for the type of relationship firms and workers begin and when and how they separate. Despite its simplicity, the environment is rich in its implications.

One of these implications is that we can examine wage inequality from a different perspective. To what extent do firing costs help shape the wage distribution? We find that a substantial increase in inequality follows an increase in the level of firing costs. This rise in inequality is due entirely to the increase in the fraction of temporary workers, which earn relatively lower wages. It is not due to an increase in the "permanent worker premium", the ratio of the wage a permanent worker earns relative to that a temporary worker.

Finally, it would be interesting to examine the role of minimal wage in shaping the employment contract composition. Likely, the minimal wage may reduce the number of temporary contracts and increase the unemployment. However, a thorough study is left for future work. 


\section{References}

[1] Aguirregabiria, V. and Alonso-Borrego, C.: 2009, "Labor Contracts and Flexibility: Evidence from a Labor Market Reform in Spain", manuscript, University of Toronto.

[2] Alonso-Borrego, C., J. Galdon-Sanchez, and J. Fernandez-Villaverde: 2002, “Evaluating Labor Market Reforms: A General Equilibrium Approach", manuscript, University of Pennsylvania.

[3] Alvarez, F. and M. Veracierto: 2000, “Labor Market Policies in an Equilibrium Search Model,", NBER Macroeconomics Annual, Vol. 14.

[4] Alvarez, F. and M. Veracierto: 2006, "Fixed-Term Employment Contracts in and Equilibrium Search Model,"NBER Working Paper 12791.

[5] Bentolila S. and G. Bertola: 1990, "Firing Costs and Labour Demand: How Bad is Eurosclerosis?", Review of Economic Studies, 57, pp. 381-402.

[6] Blanchard, O. and A. Landier: 2002, “The Perverse Effects of Partial Labour Market Reforms: Fixed-Term Contracts in France", Economic Journal, 112(480), pp. F214-F244.

[7] Bontemps, C., J-M. Robin, and G. J. van den Berg: 1999, “An Empirical Equilibrium Search Model with Search on the Job and Heterogeneous Workers and Firms", International Economic Review, 40(4), pp. 1039-1074.

[8] Cahuc, P., F. Postel-Vinay and J.M. Robin: 2006,“Wage Bargaining with On-the-Job Search: A Structural Econometric Model", Econometrica, 74(2), pp. 323-364.

[9] Cahuc, P., F. Postel-Vinay: 2002, "Temporary Jobs, Employment Protection and Labor Market Performance", Labour Economics, 9(1), pp. 63-91. 
[10] Cao, S. and D. Leung: 2010, "Stability versus Flexibility: The Role of Temporary Employment in Labour Adjustment", Bank of Canada Working Paper.

[11] Chernozhukov, V. and H. Hong: 2003, “An MCMC Approach to Classical Estimation", Journal of Econometrics, Vol. 115(2), pp. 293-346.

[12] Eckstein, Z. and K. Wolpin: 1990, “Estimating a Market Equilibrium Search Model from a Panel Data on Individuals", Econometrica, 58(4), pp. 783-808.

[13] Eckstein, Z. and G. J. van den Berg: 2007, "Empirical Labor Search: A Survey", Journal of Econometrics, 136(2), pp. 531-564.

[14] Faccini, R.: 2008, "Reassessing Labor Market Reforms: Temporary Contracts as a Screening Device", manuscript, European University Institute.

[15] Flinn, C., and J. Mabli: 2009, “On-the-Job Search, Minimum Wages and Labor Market Outcomes in an Equilibrium Bargaining Framework", manuscript, New York University.

[16] Hopenhayn, H. and R. Rogerson: 1993, “Job Turnover and Policy Evaluation: A General Equilibrium Analysis", Journal of Political Economy, 101(5), pp. 915-938.

[17] Mortensen D., and C. Pissarides: 1994, "Job Creation and Job Destruction in the Theory of Unemployment", Review of Economic Studies, 61(3), pp.397-415.

[18] Smith, E.: 2007, "Limited Duration Employment", Review of Economic Dynamics, 10(3), pp. 444-471.

[19] Venn, D.: 2009, "Legislation, Collective Bargaining and Enforcement: Updating the OECD Employment Protection Indicators", OECD Social, Employment and Migration Working Papers, 89.

[20] Wasmer, E.: 1999, "Competition for Jobs in a Growing Economy and the Emergence of Dualism", Economic Journal, 109(457), pp. 349-371. 
[21] Zhang, M.: 2008, "Cyclical Behavior of Unemployment and Job Vacancies: A Comparison between Canada and the United States,", The B.E. Journal of Macroeconomics: Vol. 8 : Iss. 1 (Topics), Article 27. 


\section{A Appendix: Proof of Propositions}

Proof of Proposition 1. Equation (19) can be written as

$$
\begin{aligned}
S^{P}(y, z)= & y+z+\beta \int_{y^{P}}^{y_{\max }} S^{P}(x, z) d F(x)+(1-\beta) f \\
& -(b-d)-\frac{\phi \alpha^{w}(\theta)\left(k+\beta \alpha^{f}(\theta) \mu_{G}(A) f\right)}{(1-\phi) \alpha^{f}(\theta)}
\end{aligned}
$$

From the fact that $\partial S^{P} / \partial y=1$ and $\partial^{2} S^{P} / \partial y \partial z=0$, it implies that $S^{P}(y, z)=y+\varphi(z)$. The integral on the right-hand side of (39) is then

$$
\begin{aligned}
\int_{y^{P}}^{y_{\max }} S^{P}(x, z) d F(x) & =\int_{y^{P}}^{y_{\max }} x+\varphi(z) d F(x) \\
& =\left.(x+\varphi(z)) F(x)\right|_{y^{P}} ^{y_{\max }}-\int_{y^{P}}^{y_{\max }} F(x) d x
\end{aligned}
$$

For any $z \in Z, S^{P}\left(y^{P}, z\right)=0$ implies $y^{P}=-\varphi(z)$. Substitute $\varphi(z)$ with $-y^{P}$, the expression of the integral is

$$
\int_{y^{P}}^{y_{\max }} S^{P}(x, z) d F(x)=\int_{y^{P}}^{y_{\max }}[1-F(x)] d x .
$$

To pin down $y^{P}$, we need to solve the equation $S^{P}\left(y^{p}, z\right)=0$, thus

$$
\begin{aligned}
y^{P}+z+\beta \int_{y^{P}}^{y_{\max }}[1-F(x)] d x= & b-d-(1-\beta) f . \\
& +\frac{\phi \alpha^{w}(\theta)\left(k+\beta \alpha^{f}(\theta) \mu_{G}(A) f\right)}{(1-\phi) \alpha^{f}(\theta)} \\
= & b-d-(1-\beta) f \\
& +\frac{\phi}{(1-\phi)}\left(\theta k+\beta \alpha^{w}(\theta) \mu_{G}(A) f\right) .
\end{aligned}
$$

Denote left-hand side by $\Phi_{z}(y)$ and right-hand side by $\Phi(\theta, d)$. Notice that $\Phi(\theta, d)$ is increasing in $\theta$ and decreasing in $d$ plus $\mu_{G}(A) \in[0,1]$, thus for any $\theta \in\left[\theta_{\min }, \theta_{\max }\right]$ 
and $d \in\left[d_{\min }, d_{\max }\right]$,

$$
\begin{array}{r}
b-d_{\max }+\frac{\phi}{1-\phi} \theta_{\min } k-(1-\beta) f<\Phi(\theta, d) \\
<b-d_{\min }+\frac{\phi}{1-\phi}\left(\theta_{\max } k+\beta \alpha^{w}\left(\theta_{\max }\right) f\right)-(1-\beta) f .
\end{array}
$$

$\Phi_{z}(y)$ is increasing in $y$ and $z$. If inequalities (22) and (23) holds then for given $\theta, d$ and $z$, we must have

$$
\Phi_{z}\left(y_{\min }\right) \leq \Phi_{z_{\max }}\left(y_{\min }\right)<\Phi(\theta, d)<\Phi_{z_{\min }}\left(y_{\max }\right) \leq \Phi_{z}\left(y_{\max }\right)
$$

We can conclude there is a unique solution $y^{P}(z) \in\left(y_{\min }, y_{\max }\right)$ for equation (41) by the intermediate value theorem. That is, $y^{P}(z)$ exists for any $z \in\left[z_{\min }, z_{\max }\right]$.

Similarly, equation (20) can be rewritten as

$$
\begin{aligned}
S^{R}(y, z)= & y+z+\beta \int_{y^{p}}^{y_{\max }}[1-F(x)] d x-c-\beta f-(b-d) \\
& -\frac{\phi \alpha^{w}(\theta)\left(k+\beta \alpha^{f}(\theta) \mu_{G}(A) f\right)}{(1-\phi) \alpha^{f}(\theta)} .
\end{aligned}
$$

Following the same argument for the condition $S^{P}\left(y^{P}, z\right)=0$, the above equation yields the cut-off value by solving:

$$
y^{R}+z+\beta \int_{y^{P}}^{y_{\max }}[1-F(x)] d x=b-d+\frac{\phi \alpha^{w}(\theta)\left(k+\beta \alpha^{f}(\theta) \mu_{G}(A) f\right)}{(1-\phi) \alpha^{f}(\theta)}+c+\beta f .
$$

Comparing equations (41) and (43), we get

$$
y^{R}=y^{P}+c+f
$$

Then assumption 2 guarantees the existence of $y^{P} \in\left(y_{\min }, y_{\max }-c-f\right)$ which implies $y^{R}<y_{\max }$ exists as well.

Proof of Proposition 2. Step 1. $E_{y} J^{P}(y, z)$ and $E_{y} J^{T}(y, z)$ are both strictly increasing in $z$. From the surplus sharing rule, it is sufficient to show that $S^{P}(y, z)$ and $S^{T}(y, z)$ 
are strictly increasing in $z$. Substitute equation (40) into (39), we obtain

$$
\begin{aligned}
S^{P}(y, z)= & y+z+\beta \int_{y^{P}(z)}^{y_{\max }}[1-F(x)] d x+(1-\beta) f-(b-d) \\
& -\frac{\phi \alpha^{w}(\theta)\left(k+\beta \alpha^{f}(\theta) \mu_{G}(A) f\right)}{(1-\phi) \alpha^{f}(\theta)} .
\end{aligned}
$$

Take the derivative of $S^{P}$ with respect to $z$, we get

$$
\frac{\partial S^{P}(y, z)}{\partial z}=1-\beta\left(1-F\left(y^{P}(z)\right)\right) y^{P \prime}(z) .
$$

From equation (41), the implicit function theorem implies that

$$
y^{P \prime}(z)=-\frac{1}{1-\beta\left(1-F\left(y^{P}\right)\right)}<0 .
$$

Plug (46) into (45), we get $\partial S^{P} / \partial z>0$. Similarly, the total surplus of a temporary contract can be rewritten as

$$
S^{T}(y, z)=y+z-b+\beta\left(1-\alpha^{w}\right) \int_{y^{P}(z)+c+f}^{y_{\max }}[1-F(x)] d x .
$$

The derivative of $S^{T}$ with respect to $z$ is given by

$$
\frac{\partial S^{T}(y, z)}{\partial z}=1-\beta\left(1-\alpha^{w}\right)\left[1-F\left(y^{P}(z)\right)\right] y^{P \prime}(z)>0 .
$$

Step 2. $E_{y} J^{P}(y, z)$ and $E_{y} J^{T}(y, z)$ are strictly convex. By the separability of $y$ and $z$, it suffices to prove that $S^{P}$ and $S^{T}$ are convex in $z$. Twice differentiate $S^{P}$ with respect to $z$, and get

$$
\frac{\partial^{2} S^{P}(y, z)}{\partial z^{2}}=\beta\left[F^{\prime}\left(y^{P \prime}\right)^{2}-\left(1-F\left(y^{P}\right)\right) y^{P \prime \prime}\right] .
$$

Since $y^{P \prime \prime}=\beta F^{\prime} y^{P \prime} /\left[1-\beta\left(1-F\left(y^{P}\right)\right)\right]^{2}<0$ and $F^{\prime}>0$, it must be the case that $\partial^{2} S^{P}(y, z) / \partial z^{2}>0$. Similarly, $\partial^{2} S^{T}(y, z) / \partial z^{2}>0$.

These two steps guarantee that if $E_{y} J^{P}(y, z)=E_{y} J^{T}(y, z)$ holds, the cut-off value $z$ 
is unique. The last step is to verify the single crossing property. That is, if

$$
\begin{aligned}
& E_{y} J^{P}\left(y, z_{\text {min }}\right)<E_{y} J^{T}\left(y, z_{\text {min }}\right), \\
& E_{y} J^{P}\left(y, z_{\text {max }}\right)>E_{y} J^{T}\left(y, z_{\text {max }}\right)
\end{aligned}
$$

hold, then the cut-off value $\bar{z}$ exists. Denote

$$
\begin{aligned}
\Delta_{\theta, d}(z)= & \frac{E_{y} J^{P}(y, z)-E_{y} J^{T}(y, z)}{1-\phi} \\
= & \beta \int_{y^{P}}^{y_{\max }}[1-F(x)] d x-\beta\left(1-\alpha^{w}(\theta)\right) \int_{y^{R}}^{y_{\max }}[1-F(x)] d x+d \\
& -\left[\frac{1}{1-\phi}-(1-\beta)\right] f-\frac{\phi}{(1-\phi)}\left(\theta k+\beta \alpha^{w}(\theta) \mu_{G}(A) f\right) . \\
= & b-\frac{1}{1-\phi} f-y^{P}-z+(E(y)+z) d \\
& -\beta\left(1-\alpha^{w}(\theta)\right) \int_{y^{R}(z)}^{y_{\max }}[1-F(x)] d x .
\end{aligned}
$$

The last equality is derived by replacing $\beta \int_{y^{P}}^{y_{\max }}[1-F(x)] d x$ with equation (41). Notice that equation (41) defines an implicit function $y^{P}\left(z, \theta, \mu_{G}, d\right)$. Totally differentiating (41) yields

$$
\begin{aligned}
\frac{\partial y^{P}}{\partial \theta} & =\frac{\phi\left(k+\beta \mu_{G} f \alpha^{w \prime}(\theta)\right)}{(1-\phi)\left[1-\beta\left(1-F\left(y^{P}\right)\right)\right]}>0, \\
\frac{\partial y^{P}}{\partial \mu_{G}} & =\frac{\phi \beta f \alpha^{w}(\theta)}{(1-\phi)\left[1-\beta\left(1-F\left(y^{P}\right)\right)\right]}>0, \\
\frac{\partial y^{P}}{\partial d} & =\frac{-1}{\left[1-\beta\left(1-F\left(y^{P}\right)\right)\right]}<0 .
\end{aligned}
$$

Then

$$
\Delta_{\theta, d}\left(z_{\min }\right) \leq b-\frac{1}{1-\phi} f-y^{P}\left(z_{\text {min }}, \theta_{\min }, 0, d\right)-z_{\text {min }}
$$

and

$$
\begin{aligned}
\Delta_{\theta, d}\left(z_{\max }\right) \geq & b-\frac{1}{1-\phi} f-y^{P}\left(z_{\max }, \theta_{\max }, 1, d\right)-z_{\max } \\
& -\beta\left(1-\alpha^{w}\left(\theta_{\min }\right)\right) \int_{y_{\min }}^{y_{\max }}[1-F(x)] d x .
\end{aligned}
$$




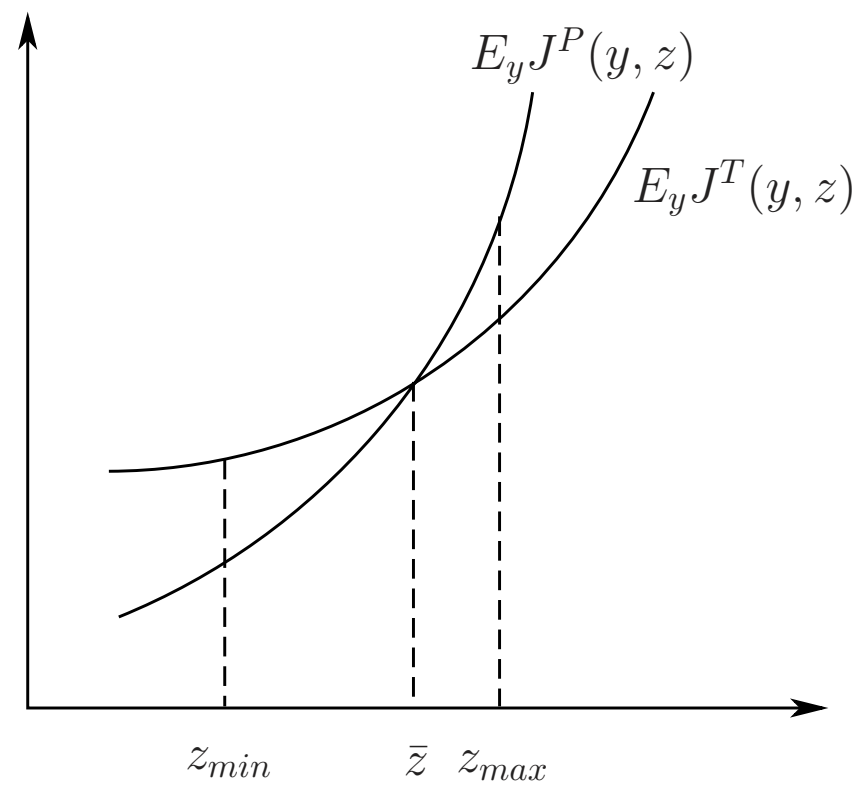

Figure 5: Permanent Contract vs. Temporary Contract

It is sufficient to show that the RHS of (48) is less than 0 and the RHS of (49) is greater than 0 . This requires

$$
\begin{aligned}
y_{1} \equiv b-\frac{1}{1-\phi} f-z_{\text {min }} & \leq y^{P}\left(z_{\text {min }}, \theta_{\text {min }}, 0, d\right), \\
b-\frac{1}{1-\phi} f-z_{\max } & \geq y^{P}\left(z_{\max }, \theta_{\max }, 1, d\right) . \\
y_{2} \equiv-\beta\left(1-\alpha^{w}\left(\theta_{\min }\right)\right) \int_{y_{\min }}^{y_{\max }}[1-F(x)] d x &
\end{aligned}
$$

Denote $\left(y^{P}\right)^{-1}$ the inverse mapping of $y$ into $d$. Since $y^{P}$ is monotonically decreasing in $d$, the above inequalities imply

$$
\left(y^{P}\right)^{-1}\left(y_{2} \mid z_{\max }, \theta_{\max }, 1\right) \leq d \leq\left(y^{P}\right)^{-1}\left(y_{1} \mid z_{\min }, \theta_{\min }, 0\right)
$$

Figure A shows the single crossing property.

Proof of Proposition 3. It is sufficient to consider a permanent worker to search onthe-job only for one period. Using (3) and (9) yields the total surplus for a permanent 
match of:

$$
\begin{aligned}
S_{s}^{P}(y, z)= & J_{s}^{P}(y, z)-(Q-f)+V_{s}^{P}(y, z)-U \\
= & y+z+\left[1-\left(1-\alpha^{w}(\theta)\right)\right] \beta f-(b-d) \\
& +\beta\left(1-\alpha^{w}(\theta) \int_{y_{\min }}^{y_{\max }} \max \left(S^{P}(y, z), 0\right) d F(x)\right.
\end{aligned}
$$

If the permanent worker does not search, the total surplus $S^{P}(y, z)$ is given by equation (19). What we need to show is

$$
S^{P}(y, z) \geq S_{s}^{P}(y, z)
$$

for any $y$ and $z \geq \bar{z}$. Using (19), (50) and the fact (40), the above inequality holds if and only if

$$
d \geq \frac{\phi}{1-\phi}\left(\theta k+\beta \alpha^{w}(\theta) \mu_{G}(A) f\right)-\beta \alpha^{w}(\theta)\left(\int_{y^{P}}^{y_{\max }}[1-F(x)] d x-f\right) .
$$

Denote the right hand side of (51) by $\Lambda$.

$$
\Lambda \leq \frac{\phi}{1-\phi}\left(\theta_{\max } k+\beta \alpha^{w}\left(\theta_{\max }\right) f\right)-\beta \alpha^{w}\left(\theta_{\min }\right)\left(\int_{y^{P}\left(z_{\min }, \theta_{\max }, 1, d_{\min }\right)}^{y_{\max }}[1-F(x)] d x-f\right) .
$$

Because $d \geq d_{\min }$, if

$$
\left.\begin{array}{rl}
d_{\text {min }} & =\max \left\{\begin{array}{c}
\frac{\phi}{1-\phi}\left(\theta_{\max } k+\beta \alpha^{w}\left(\theta_{\max }\right) f\right) \\
0 d_{3}
\end{array}-\beta \alpha^{w}\left(\theta_{\min }\right)\left(\int_{y^{P}\left(z_{\min }, \theta_{\max }, 1, d_{\min }\right)}^{y^{2}}[1-F(x)] d x-f\right)\right.
\end{array}\right\}
$$

inequality (51) holds. Similar argument can show that the newly promoted worker will have no incentive to search.

We now show that temporary workers have an incentive to search on the job. Suppose temporary workers do not search for one period. Using (5) and (14) generates the 
surplus as:

$$
\begin{aligned}
S_{n}^{T}= & y+z+\beta \int_{y_{\min }}^{y_{\max }} \max \left(S^{R}(x, z), 0\right) d F(x) \\
& -(b-d)-\frac{\phi}{1-\phi} \theta\left(k+\beta \alpha^{f}(\theta) \mu_{G}(A) f\right)
\end{aligned}
$$

If temporary workers do search then the surplus is defined by equation (21). Then $S^{T}(y, z) \geq S_{n}^{T}(y, z)$ requires

$$
d \leq \frac{\phi}{1-\phi}\left(\theta k+\beta \alpha^{w}(\theta) \mu_{G}(A) f\right)-\beta \alpha^{w}(\theta) \int_{y^{R}}^{y_{\max }}[1-F(x)] d x .
$$

The right hand side of (51) denoted by $\Lambda$ must not less than

$$
\frac{\phi}{1-\phi} \theta_{\min } k-\beta \alpha^{w}\left(\theta_{\max }\right) \int_{y^{R}\left(z_{\max }, \theta_{\min }, 0, d_{\max }\right)}^{y_{\max }}[1-F(x)] d x .
$$

Then for any $d \leq d_{\max }$, if

$$
\begin{aligned}
d_{\max } & =\frac{\phi}{1-\phi} \theta_{\min } k-\beta \alpha^{w}\left(\theta_{\max }\right) \int_{y^{R}\left(z_{\max }, \theta_{\min ,}, 0, d_{\max }\right)}^{y_{\max }}[1-F(x)] d x \\
& \equiv d_{4}
\end{aligned}
$$

temporary workers have an incentive to search on the job.

Combine conditions in Proposition 2, we have $d_{\min }=\max \left(d_{1}, d_{3}\right)$ and $d_{\max } \equiv$ $\min \left(d_{2}, d_{4}\right)$.

Proof of Proposition 4. The equilibrium condition for $\bar{z}$ is $E_{y} J^{P}(y, \bar{z})=E_{y} J^{T}(y, \bar{z})$. By using the sharing rule (16) and equations (19) and (21), it implies that

$$
\begin{array}{r}
\beta \int_{\bar{y}^{P}}^{y_{\max }}(1-F(x)) d x-\left[\frac{1}{1-\phi}-(1-\beta)\right] f-\frac{\phi\left(\theta k+\beta \alpha^{w}(\theta)(1-G(\bar{z})) f\right)}{(1-\phi)} \\
+d-\beta\left(1-\alpha^{w}\right) \int_{\bar{y}^{R}}^{y_{\max }}(1-F(x)) d x=0
\end{array}
$$


where $\bar{y}^{P} \equiv y^{P}(\bar{z})$ and $\bar{y}^{R} \equiv y^{R}(\bar{z})=\bar{y}^{P}+c+f$. From equation (25), we have

$$
\begin{aligned}
\bar{y}^{P}+\bar{z}+\beta \int_{\bar{y}^{P}}^{y_{\max }}(1-F(x)) d x & +(1-\beta) f \\
& -(b-d)-\frac{\phi\left(\theta k+\beta \alpha^{w}(\theta)(1-G(\bar{z})) f\right)}{(1-\phi)}=0 .
\end{aligned}
$$

Denote the left hand sides of equations (55) and (56) by $\Pi\left(\bar{y}^{P}, \bar{z}\right)$. Totally differentiate $\Pi$, we get

$$
D_{\left(\bar{y}^{P}, \bar{z}\right)} \Pi=\left[\begin{array}{cc}
1-\beta\left(1-F\left(\bar{y}^{P}\right)\right) & 1+\frac{\phi}{1-\phi} \alpha^{w} \beta f G^{\prime}(\bar{z}) \\
-\beta\left[1-F\left(\bar{y}^{P}\right)-\left(1-\alpha^{w}\right)\left(1-F\left(\bar{y}^{R}\right)\right)\right] & \frac{\phi}{1-\phi} \alpha^{w} \beta f G^{\prime}(\bar{z})
\end{array}\right],
$$

and

$$
\begin{aligned}
& D_{f} \Pi= {\left[\begin{array}{c}
1-\beta-\frac{\phi}{1-\phi} \alpha^{w} \beta(1-G(\bar{z})) \\
-\left[\frac{1}{1-\phi}-(1-\beta)\right]+\beta\left(1-\alpha^{w}\right)\left(1-F\left(\bar{y}^{R}\right)\right)-\frac{\phi}{1-\phi} \alpha^{w} \beta(1-G(\bar{z}))
\end{array}\right], } \\
& D_{\alpha^{w} \Pi=}=\left[\begin{array}{c}
-\frac{\phi}{(1-\phi) \alpha^{f}}\left[k+\beta \alpha^{f}(1-G(\bar{z})) f\right] \\
\int_{\bar{y}^{R}}^{y_{\max }}(1-F(x)) d x-\frac{\phi}{(1-\phi) \alpha^{f}}\left[k+\beta \alpha^{f}(1-G(\bar{z})) f\right]
\end{array}\right], \\
& D_{c} \Pi=\left[\begin{array}{c}
0 \\
\beta\left(1-\alpha^{w}\right)\left(1-F\left(\bar{y}^{R}\right)\right)
\end{array}\right] .
\end{aligned}
$$

The determinant of matrix $D_{\left(\bar{y}^{p}, \bar{z}\right)} \Pi$ is

$$
\begin{aligned}
\left|D_{\left(\bar{y}^{P}, \bar{z}\right)} \Pi\right|= & \beta\left[1-F\left(\bar{y}^{P}\right)-\left(1-\alpha^{w}\right)\left(1-F\left(\bar{y}^{R}\right)\right)\right] \\
& +\left[1-\beta\left(1-\alpha^{w}\right)\left(1-F\left(\bar{y}^{R}\right)\right)\right]\left[\frac{\phi}{1-\phi} \alpha^{w} \beta f G^{\prime}(\bar{z})\right] \\
> & 0,
\end{aligned}
$$

since $F\left(\bar{y}^{P}\right)<F\left(\bar{y}^{R}\right)$ and $G^{\prime}(z)>0$. Apply the implicit function theorem, we can calculate the following:

$$
\frac{d \bar{z}}{d f}=-\frac{a_{1}+a_{2}}{\left|D_{\left(\bar{y}^{p}, \bar{z}\right)} \Pi\right|}
$$

where

$$
a_{1}=\beta\left[1-F\left(\bar{y}^{P}\right)-\left(1-\alpha^{w}\right)\left(1-F\left(\bar{y}^{R}\right)\right)\right]\left(1-\beta-\frac{\phi}{1-\phi} \alpha^{w} \beta(1-G(\bar{z}))\right)
$$


and

$$
\begin{aligned}
a_{2}= & {\left[1-\beta\left(1-F\left(\bar{y}^{P}\right)\right)\right]\left\{-\left[\frac{1}{1-\phi}-(1-\beta)\right]\right.} \\
& \left.+\beta\left(1-\alpha^{w}\right)\left(1-F\left(\bar{y}^{R}\right)\right)+\frac{\phi}{1-\phi} \alpha^{w} \beta(1-G(\bar{z}))\right\} .
\end{aligned}
$$

Observe that the numerator $\left(a_{1}+a_{2}\right)$ is decreasing in $\phi$. When $\phi=0$, the numerator becomes

$$
\begin{aligned}
a_{1}+a_{2}= & \beta(1-\beta)\left[1-F\left(\bar{y}^{P}\right)-\left(1-\alpha^{w}\right)\left(1-F\left(\bar{y}^{R}\right)\right)\right] \\
& -\beta\left[1-\beta\left(1-F\left(\bar{y}^{P}\right)\right)\right]\left[1-\left(1-\alpha^{w}\right)\left(1-F\left(\bar{y}^{R}\right)\right)\right] .
\end{aligned}
$$

Because $1-\beta<1-\beta\left(1-F\left(\bar{y}^{P}\right)\right)$ and $1-F\left(\bar{y}^{P}\right)-\left(1-\alpha^{w}\right)\left(1-F\left(\bar{y}^{R}\right)\right)<1-$ $\left(1-\alpha^{w}\right)\left(1-F\left(\bar{y}^{R}\right)\right)$, we must have $a_{1}+a_{2}<0$. Hence, for any $\phi, d \bar{z} / d f>0$.

$$
\frac{d \bar{z}}{d \alpha^{w}}=-\frac{a_{3}}{\left|D_{\left(\bar{y}^{p}, \bar{z}\right)} \Pi\right|},
$$

where

$$
\begin{aligned}
a_{3}= & \beta\left[1-F\left(\bar{y}^{P}\right)-\left(1-\alpha^{w}\right)\left(1-F\left(\bar{y}^{R}\right)\right)\right]\left\{-\frac{\phi}{(1-\phi) \alpha^{f}}\left[k+\beta \alpha^{f}(1-G(\bar{z})) f\right]\right\} \\
& +\left[1-\beta\left(1-F\left(\bar{y}^{P}\right)\right)\right]\left\{\int_{\bar{y}^{R}}^{y_{\max }}(1-F(x)) d x\right. \\
& \left.-\frac{\phi}{(1-\phi) \alpha^{f}}\left[k+\beta \alpha^{f}(1-G(\bar{z})) f\right]\right\} .
\end{aligned}
$$

Again, $a_{3}$ is decreasing in $\phi$. When $\phi \rightarrow 0, a_{3} \rightarrow\left[1-\beta\left(1-F\left(\bar{y}^{P}\right)\right)\right] \int_{\bar{y}^{R}}^{y_{\max }}(1-F(x)) d x>$ 0 , while $\phi \rightarrow 1, a_{3} \rightarrow-\infty$. Therefore there exists $\bar{\phi}$ such that

$$
\begin{gathered}
\begin{cases}\frac{d \bar{z}}{d \alpha^{w}}<0 & \text { when } \phi<\bar{\phi} \\
\frac{d \bar{z}}{d \alpha^{w}}>0 & \text { when } \phi>\bar{\phi}\end{cases} \\
\frac{d \bar{z}}{d c}=-\frac{\left[1-\beta\left(1-F\left(\bar{y}^{P}\right)\right)\right] \beta\left(1-\alpha^{w}\right)\left(1-F\left(\bar{y}^{R}\right)\right)}{\left|D_{\left(\bar{y}^{P}, \bar{z}\right)} \Pi\right|} \\
<0 .
\end{gathered}
$$


Proof of Proposition 5. Suppose $\phi \rightarrow 0$, equation (41) implies

$$
\begin{aligned}
\frac{d y^{P}}{d f} & =-\frac{1-\beta-\frac{\phi}{1-\phi} \alpha^{w} \beta(1-G(\bar{z}))+\frac{\phi}{1-\phi} \alpha^{w} \beta f G^{\prime}(\bar{z}) \frac{d \bar{z}}{d f}}{1-\beta\left(1-F\left(\bar{y}^{P}\right)\right)} \\
& <0, \\
\frac{d y^{P}}{d \alpha^{w}} & =-\frac{-\frac{\phi}{(1-\phi) \alpha^{f}}\left[k+\beta \alpha^{f}(1-G(\bar{z})) f\right]+\frac{\phi}{1-\phi} \alpha^{w} \beta f G^{\prime}(\bar{z}) \frac{d \bar{z}}{d \alpha^{w}}}{1-\beta\left(1-F\left(\bar{y}^{P}\right)\right)} \\
& >0, \\
\frac{d y^{P}}{d c} & =-\frac{\frac{\phi}{1-\phi} \alpha^{w} \beta f G^{\prime}(\bar{z}) \frac{d \bar{z}}{d c}}{1-\beta\left(1-F\left(\bar{y}^{P}\right)\right)} \rightarrow 0^{+} .
\end{aligned}
$$

Use these facts and combine equation (43), we derive

$$
\begin{aligned}
\frac{d y^{R}}{d f} & =\frac{\beta F\left(y^{P}\right)-\frac{\phi}{1-\phi} \alpha^{w} \beta\left[(1-G(\bar{z}))-f G^{\prime}(\bar{z}) \frac{d \bar{z}}{d f}\right]}{1-\beta\left(1-F\left(\bar{y}^{P}\right)\right)}>0, \\
\frac{d y^{R}}{d \alpha^{w}} & =\frac{d y^{P}}{d \alpha^{w}}>0, \\
\frac{d y^{R}}{d f} & =1+\frac{\frac{\phi}{1-\phi} \alpha^{w} \beta f G^{\prime}(\bar{z}) \frac{d \bar{z}}{d c}}{1-\beta\left(1-F\left(\bar{y}^{P}\right)\right)}>0 .
\end{aligned}
$$

Proof of Proposition 6. The job creation rule is obtained by equation (17). Substitute equations (19) and (21) into (17), we get

$$
\begin{gathered}
E(y+z)-b(1-d)-\int_{z_{\min }}^{\bar{z}} d(E(y)+z) d G(z)+(1-\beta)(1-G(\bar{z})) f \\
-\frac{\beta+\phi \alpha^{w}(\theta)(1-G(\bar{z}))}{(1-\phi) \beta \alpha^{f}(\theta)}\left[k+\beta f(1-G(\bar{z})) \alpha^{f}(\theta)\right] \\
+\beta\left(1-\alpha^{w}(\theta)\right) \int_{z_{\min }}^{\bar{z}} \int_{y^{P}(z)+c+f}^{y_{\max }}(1-F(x)) d x d z \\
+\beta \int_{\bar{z}}^{z_{\max }} \int_{y^{P}(z)}^{y_{\max }}(1-F(x)) d x d z=0
\end{gathered}
$$

Denote the left hand side of equation (57) by $h$ and differentiate it with respect to $\theta, f$ 
and $c$, one gets:

$$
\begin{aligned}
\frac{\partial h}{\partial \theta}= & -\beta \alpha^{w \prime} \int_{z_{\min }}^{\bar{z}} \int_{y^{P}(z)+c+f}^{y_{\max }}(1-F(x)) d x d z \\
& -\frac{k\left[\phi(1-G(\bar{z})) \alpha^{f} \alpha^{w \prime}-\left[\beta+\phi \alpha^{w}(\theta)(1-G(\bar{z}))\right] \alpha^{f \prime}\right]}{(1-\phi) \beta\left(\alpha^{f}\right)^{2}} \\
& -\frac{\beta+\phi \alpha^{w}(1-G(\bar{z}))}{(1-\phi)}(1-G(\bar{z})) \alpha^{w \prime} \\
< & 0,
\end{aligned}
$$

due to $\alpha^{w \prime}(\theta)>0$ and $\alpha^{f \prime}(\theta)<0$,

$$
\begin{aligned}
\frac{\partial h}{\partial f}= & (1-\beta)(1-G(\bar{z}))-\frac{\beta+\phi \alpha^{w}(1-G(\bar{z}))}{(1-\phi)}(1-G(\bar{z})) \\
& -\beta\left(1-\alpha^{w}\right) \int_{z_{\min }}^{\bar{z}}\left(1-F\left(y^{R}(z)\right)\right) d z .
\end{aligned}
$$

$\partial h / \partial f$ is negative provided that $\beta>1 / 2$. Hence

$$
\frac{d \theta}{d f}=-\frac{\partial h / \partial f}{\partial h / \partial \theta}<0
$$

Finally, since

$$
\frac{\partial h}{\partial c}=-\beta\left(1-\alpha^{w}\right) \int_{z_{\min }}^{\bar{z}}\left(1-F\left(y^{R}(z)\right)\right) d z<0,
$$

we can conclude that

$$
\frac{d \theta}{d c}=-\frac{\partial h / \partial c}{\partial h / \partial \theta}<0
$$




\section{B Model Solution and Estimation}

This section describes some technical aspects of the solution and estimation algorithms that produce the results shown in section 7. The model described can be defined as a function $\Xi: \Gamma \rightarrow \tilde{Y}$, where $\gamma \in \Gamma \subset \mathbb{R}^{n_{\gamma}}$, and $\tilde{y} \in \tilde{Y} \subset \mathbb{R}^{n_{M}}$. An element in the set $\tilde{Y}$ can be thought of an endogenous variable (e.g. the unemployment rate) that is an outcome of the model. The estimation procedure uses a statistical criterion function that minimizes the deviations of model-implied moments - weighted appropriately from empirical moments.

Empirical moments are given by the means of time series that have a model-implied moment as a counterpart. Given a vector of time series of length $T$ denoted by $\mathbf{Y}_{T}=$ $\left\{Y_{T}^{1}, \ldots, Y_{T}^{n_{M}}\right\}$ define the vector $M_{n_{M} \times 1}$ as having typical element $m_{j}=\left(\tilde{y}(\gamma)-\bar{Y}_{T}^{j}\right)$ with $j=1, \ldots, n_{M}$ and $\bar{Y}_{T}^{j}=(1 / T) \sum_{t=1}^{T} y_{t}$. We construct the statistical criterion function,

$$
H\left(\gamma, \mathbf{Y}_{T}\right)=M\left(\gamma, \mathbf{Y}_{T}\right)^{\prime} W\left(\gamma, \mathbf{Y}_{T}\right) M\left(\gamma, \mathbf{Y}_{T}\right)
$$

We sensibly choose the matrix $W\left(\gamma, \mathbf{Y}_{T}\right)$ to be the inverse of the variance matrix of $\mathbf{Y}_{T}$. In our application $n_{M}=13$ and $n_{\gamma}=8$, since the parameter vector of interest is given by $\gamma=\left(f, b, \phi, \xi, k, \mu_{y}, \mu_{z}, \sigma_{y}\right)$. In principle one can obtain an estimate of $\gamma$ by:

$$
\hat{\gamma}=\underset{\gamma}{\operatorname{argmin}} H\left(\gamma, \mathbf{Y}_{\mathbf{T}}\right)
$$

Minimizing the function $H\left(\gamma, \mathbf{Y}_{\mathbf{T}}\right)$ by means of standard minimization routines e.g. any optimizer in the family of Newton-type methods, is seldom an easy task. Problems abound, and they include non-differentiabilities, flat areas, and local minima. To obtain estimates of $\gamma$ we employ a Markov Chain Monte Carlo method (MCMC) that transforms the function $H\left(\gamma, \mathbf{Y}_{T}\right)$ into a proper density function. This transformation is given by:

$$
p\left(\gamma, \mathbf{Y}_{T}\right)=\frac{e^{H\left(\gamma, \mathbf{Y}_{T}\right)}}{\int_{\Gamma} e^{H\left(\gamma, \mathbf{Y}_{T}\right)} d \gamma}
$$

where $\pi(\gamma)$ is a prior distribution (or weight function) over the parameter space. This distribution can be uniform which implies a constant $\pi(\gamma)$ and we assume so in the estimation. Chernozhukov and Hong (2003) label $p\left(\gamma, \mathbf{Y}_{T}\right)$ a quasi-posterior density because it is not a posterior density function in a true Bayesian sense; there is no updating. It is, however, a proper density function with well-defined moments and as a result we can define, for instance, the quasi-posterior mean as:

$$
\hat{\gamma}=\int_{\Gamma} \gamma p\left(\gamma, \mathbf{Y}_{T}\right) d \gamma
$$

In practice, the way we compute the quasi-posterior mean is by a Monte Carlo 
procedure. Markov Chain Monte Carlo amounts to simulating a Markov Chain that converges to the quasi-posterior distribution. Beginning with an initial guess for the parameter vector $\gamma^{0}$, we iterate on the following algorithm:

1. Draw a candidate vector $\gamma^{i}$ from a distribution $q\left(\gamma^{i} \mid \gamma^{i-1}\right)$.

2. Compute $e^{H\left(\gamma^{i}, \mathbf{Y}_{T}\right)}$.

3. If $p_{A}=\frac{e^{H\left(\gamma^{i}, \mathbf{Y}_{T}\right)}}{e^{H\left(\gamma^{i-1}, \mathbf{Y}_{T}\right)}} \geq 1$, accept $\gamma^{i}$.

4. Else, accept $\gamma^{i}$ with probability $p_{A}$.

5. Set $i \leftarrow i+1$ and return to Step 1 .

Repeating these 5 steps and generating a long sequence of draws for $\gamma$ yields a sample of large size, hopefully drawn from the quasi posterior density $p\left(\gamma, \mathbf{Y}_{T}\right) .{ }^{25}$ Any moment of interest (means, standard deviations, quantiles, etc...) can be readily computed. To evaluate the function $e^{H}\left(\gamma, \mathbf{Y}_{T}\right)$ one needs to solve for the model counterparts of the empirical series in $\mathbf{Y}_{T}$. For a given $\gamma^{i}$ in the sequence of simulated draws, we obtain a model solution using the following steps:

1. We begin with guesses for $\theta$, and $\bar{z}^{26}$

2. Find the surplus functions $S^{P}, S^{R}$ and $S^{T}$ by substituting and combining equations (19), (20), (21), (42), (44), and (47).

3. Update $\theta$ using equation (17). Using the functional form for the matching function specified above, $\theta$ is given by:

$$
\theta=\left(\left(\frac{\Phi}{k}\right)^{\xi}-1\right)^{\frac{1}{\xi}}
$$

and

$$
\begin{aligned}
\Phi= & \int_{z_{\min }}^{z_{\max }}\left[\mathbb{I}_{A} E_{y} S^{P}(y, z)+\left(1-\mathbb{I}_{A}\right) E_{y} S^{T}(y, z)\right] d G(z)(1-\phi) \beta \\
& -\beta f \mu_{G}(A) .
\end{aligned}
$$

There are two important things to consider in this step. First, the initial guess of $\theta$ is important. Not all values of $\theta$ converge. Second, due to the degree of nonlinearity in our problem, we dampen the speed of updating $\theta$ by heavily weighting the previous value. We set the updated value $\theta_{N E W}$ to be equal to $\lambda \theta_{O L D}+(1-\lambda) \theta$ where $\lambda$ is 0.9 (updating is slow).

\footnotetext{
${ }^{25}$ We used 5,000 simulations and discarded the first 1,000.

${ }^{26}$ We hope it is clear to the reader the implicit dependence of these variables on $\gamma^{i}$.
} 
4. Update $\bar{z}$ by solving the two-equation system defined by equations (55) and (56), which solve for $\bar{z}$ and $y^{P}(\bar{z})$.

5. Iterate on the previous two steps until the sequences of $\theta$ and $\bar{z}$ have converged.

6. Having obtained $\bar{z}$ and $\theta$ we can update the employment measures - both temporary and permanent - using the steady-state versions of equations (32) and (33). These are given by:

$$
\begin{aligned}
n^{P}= & \frac{\left(u+n^{T}\right) \alpha^{w}(\theta)(1-G(\bar{z}))}{1-\int_{z_{\min }}^{z_{\max }}\left[1-F\left(y^{P}(z)\right)\right] d G(z)} \\
& +\frac{\left(1-\alpha^{w}(\theta)\right) \int_{z_{\min }}^{\bar{z}}\left[1-F\left(y^{R}(z)\right)\right] d G(z) n^{T}}{1-\int_{z_{\min }}^{z_{\max }}\left[1-F\left(y^{P}(z)\right)\right] d G(z)} .
\end{aligned}
$$

and,

$$
n^{T}=\frac{u \alpha^{w}(\theta) G(\bar{z})}{1-\alpha^{w}(\theta) G(\bar{z})}
$$

All integrals throughout are evaluated using quadrature. With values for $\theta, \bar{z}, n^{T}$, $n^{P}$ (and clearly $u$ as a byproduct), one can compute wages and simulate histories of workers to fit regression equation (37). In addition, it is easy to compute other moments. In what follows we summarize how we compute the measures of turnover for the different groups of workers.

- Job destruction rate for all workers:

$$
J D=\int_{z_{\min }}^{z_{\max }} F\left(Y^{P}(z)\right) d G(z) \frac{n^{P}}{n^{P}+n^{T}}+\left(1-\alpha^{w}\right) \frac{1}{G(\bar{z})} \int_{z_{\min }}^{\bar{z}} F\left(Y^{R}(z)\right) d G(z) \frac{n^{T}}{n^{P}+n^{T}}
$$

- Job creation rate for all workers:

$$
J C=\frac{u}{n^{T}+n^{P}} \alpha^{w}
$$

- Job destruction rate for permanent workers:

$$
J D_{P}=\int_{z_{\min }}^{z_{\max }} F\left(Y^{P}(z)\right) d G(z) \frac{n^{P}}{n^{P}+n^{T}}
$$

- Job creation rate for permanent workers:

$$
J C_{P}=\alpha^{w}(1-G(\bar{z})) \frac{n^{T}+u}{n^{P}+n^{T}}+\left(1-\alpha^{w}\right) \int_{z_{\min }}^{\bar{z}}\left(1-F\left(Y^{R}(z)\right)\right) d G(z) \frac{n^{T}}{n^{P}+n^{T}}
$$


- Job destruction rate for temporary workers:

$$
J D_{T}=\left(1-\alpha^{w}\right) \frac{n^{T}}{n^{T}+n^{P}}+\alpha^{w}(1-G(\bar{z})) \frac{n^{T}}{n^{P}+n^{T}}
$$

- Job destruction rate for temporary workers:

$$
J C_{T}=\alpha^{w} G(\bar{z}) \frac{u}{n^{P}+n^{T}}
$$

